Universidade de São Paulo

Escola Superior de Agricultura "Luiz de Queiroz"

\title{
Predição genômica de híbridos de milho para caracteres de arquitetura oligogênica e sob diferentes parâmetros de penalização e correção de fenótipo
}

\section{Giovanni Galli}

Dissertação apresentada para obtenção do título de Mestre em Ciências. Área de concentração: Genética e Melhoramento de Plantas 
Giovanni Galli

Engenheiro Agrônomo

Predição genômica de híbridos de milho para caracteres de arquitetura oligogênica e sob diferentes parâmetros de penalização e correção de fenótipo

versão revisada de acordo com a resolução CoPGr 6018 de 2011

Orientador:

Prof. Dr. ROBERTO FRITSCHE NETO

Dissertação apresentada para obtenção do título de Mestre em Ciências. Área de concentração: Genética e Melhoramento de Plantas

\section{Piracicaba}




\section{Dados Internacionais de Catalogação na Publicação DIVISÃO DE BIBLIOTECA - DIBD/ESALQ/USP}

\section{Galli, Giovanni}

Predição genômica de híbridos de milho para caracteres de arquitetura oligogênica e sob diferentes parâmetros de penalização e correção de fenótipo / Giovanni Galli. - versão revisada de acordo com a resolução CoPGr 6018 de 2011. - - Piracicaba, 2016.

71 p. : il.

Dissertação (Mestrado) - - Escola Superior de Agricultura "Luiz de Queiroz".

1. Seleção genômica 2. BLUE 3. BLUP 4. Capacidade preditiva 5. Arquitetura genética I. Título 
DEDICATÓRIA

À minha família. Dedico 


\section{AGRADECIMENTOS}

À minha família pelo apoio, educação e amor incondicional.

À Escola Superior de Agricultura "Luiz de Queiroz" pela formação.

Ao Professor Dr. Roberto Fritsche Neto pela oportunidade, ensinamentos, orientação e exemplo profissional.

Aos colegas do Laboratório de Melhoramento de Plantas Alógamas pelo auxílio sempre que necessário e pela amizade que levarei para toda a vida.

Aos funcionários da universidade, em especial a Miguel Ribeiro de Camargo Filho pela inestimável contribuição na condução dos experimentos e pelos momentos de descontração.

À empresa Helix Sementes pela parceria, especialmente ao Dr. Caillet Dornelles Marinho pela contribuição com informações necessárias ao desenvolvimento deste trabalho.

À CAPES - Coordenação de Aperfeiçoamento de Pessoal de Nível Superior - pela concessão da bolsa durante os dois anos de mestrado.

Àqueles aqui não mencionados que contribuíram para a realização deste trabalho. 


\section{SUMÁRIO}

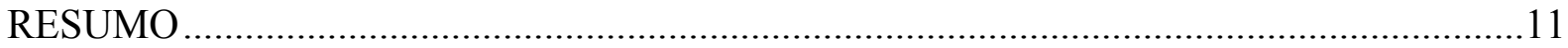

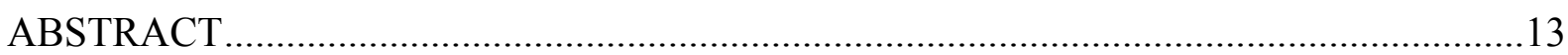

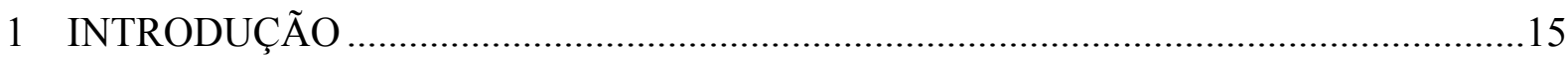

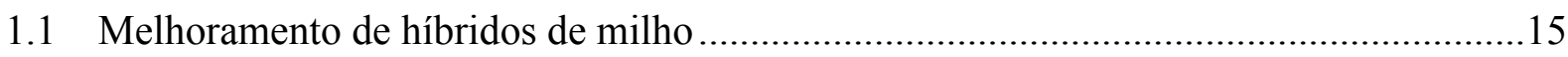

1.2 Seleção genômica no melhoramento de plantas ........................................................... 16

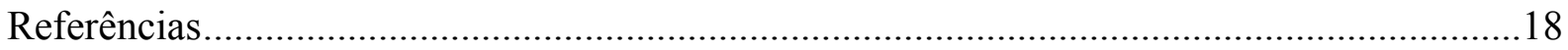

2 EFEITO DO PARÂMETRO DE PENALIZAÇÃO E DA CORREÇÃO DO FENÓTIPO NA PREDIÇÃO GENÔMICA DE HÍBRIDOS SIMPLES DE MILHO TROPICAL ............21

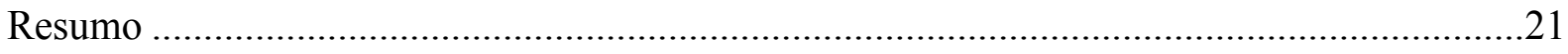

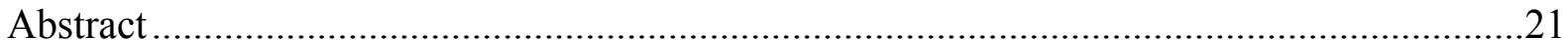

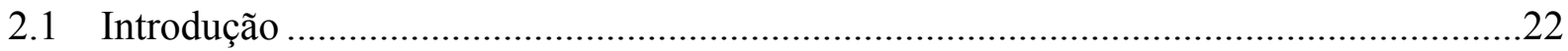

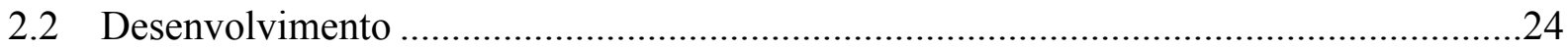

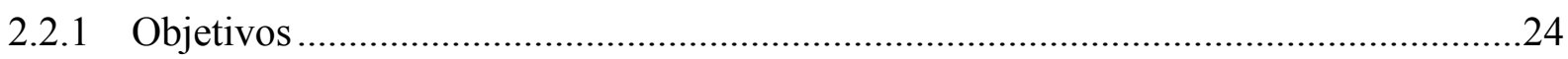

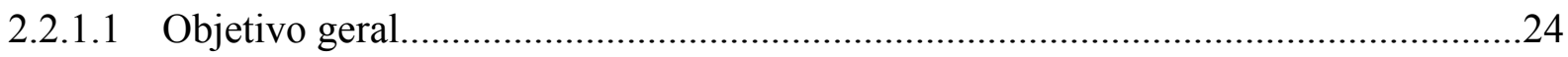

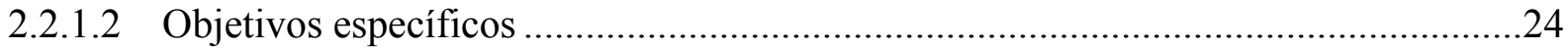

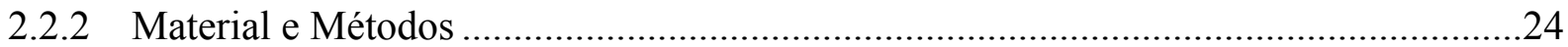

2.2.2.1 População de treinamento e obtenção de dados fenotípicos ......................................24

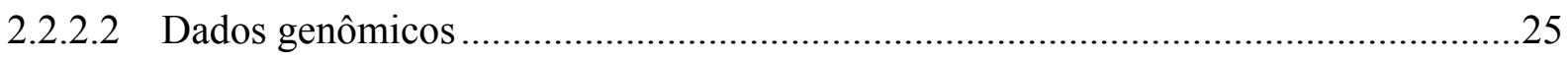

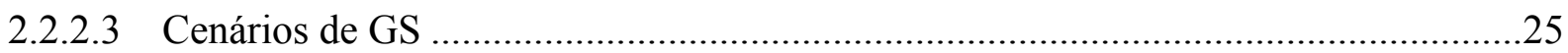

2.2.2.4 Obtenção dos valores genotípicos e médias ajustadas ............................................26

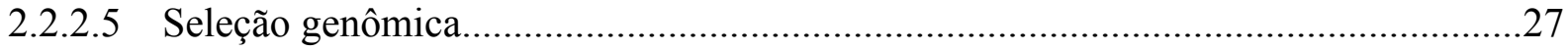

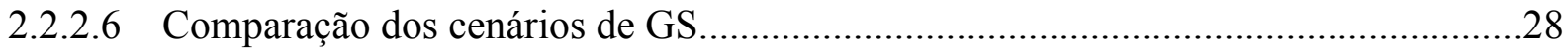

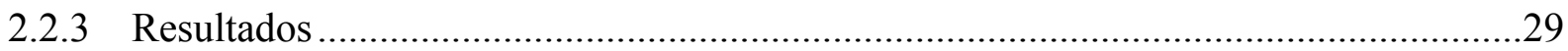

2.2.3.1 Análise de Deviance e estimativa dos parâmetros genéticos..................................29

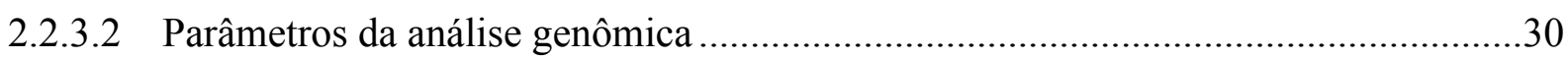

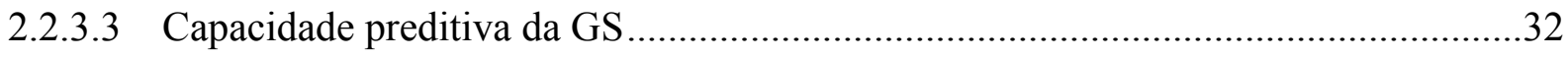

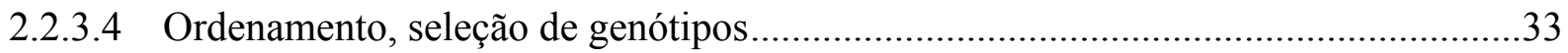

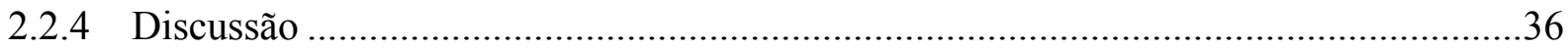

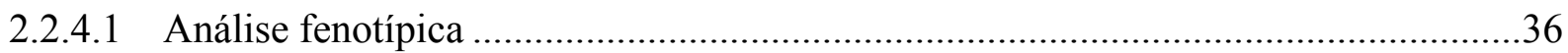

2.2.4.2 Controle de qualidade e composição do genótipo dos híbridos.................................37

2.2.4.3 Efeito do parâmetro de penalização nas análises genômicas......................................38

2.2.4.4 Efeito da correção do fenótipo na GS ......................................................................39 


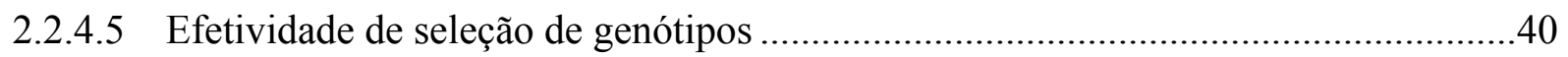

2.2.4.6 Aplicação dos resultados no melhoramento de plantas ...........................................41

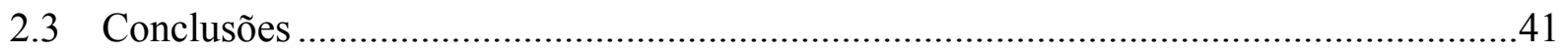

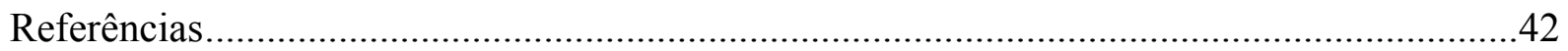

3 PREDIÇÃO GENÔMICA DE HÍBRIDOS SIMPLES DE MILHO TROPICAL PARA CARACTERES OLIGOGÊNICOS VIA MÉTODOS QUE CONSIDERAM SNPS DE

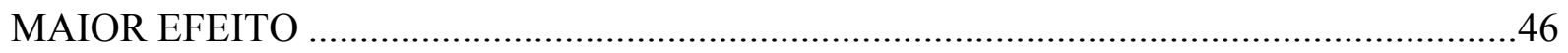

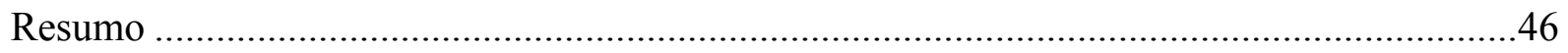

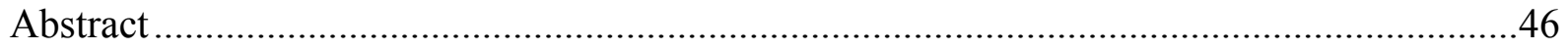

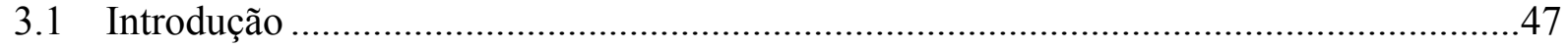

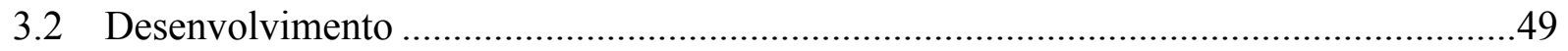

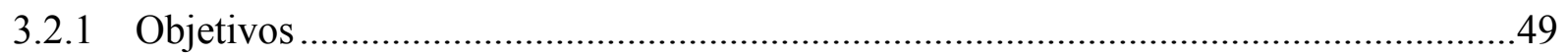

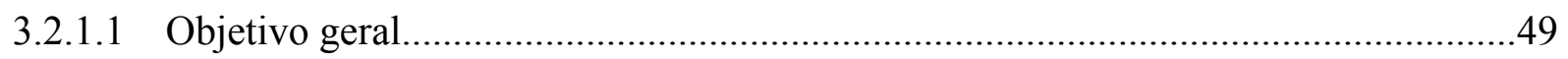

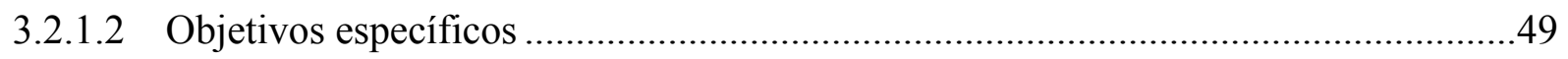

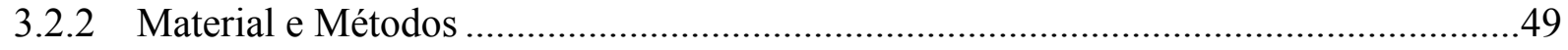

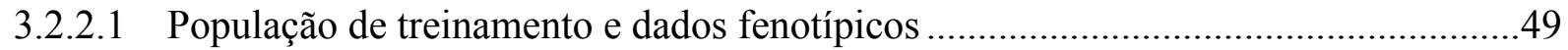

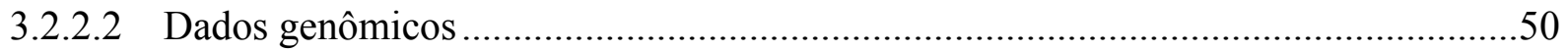

3.2.2.3 Análise de Deviance e predição dos valores genotípicos .........................................50

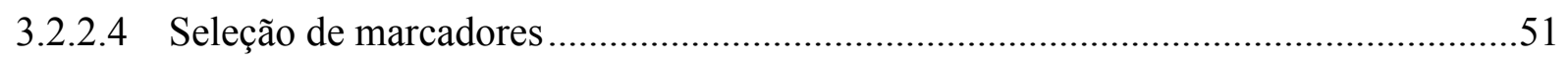

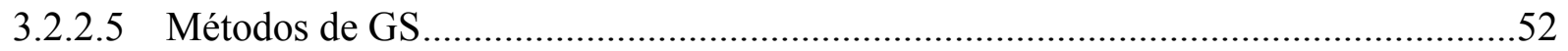

3.2.2.6 Obtenção das capacidades preditivas por validação cruzada.....................................54

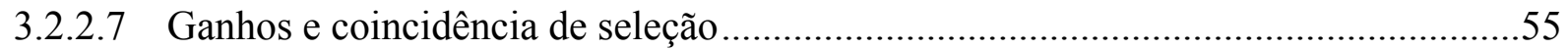

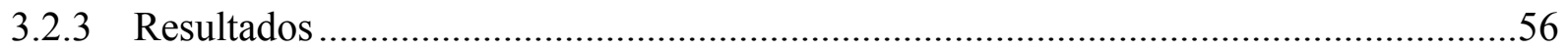

3.2.3.1 Análise de Deviance e estimativa dos parâmetros genéticos ....................................56

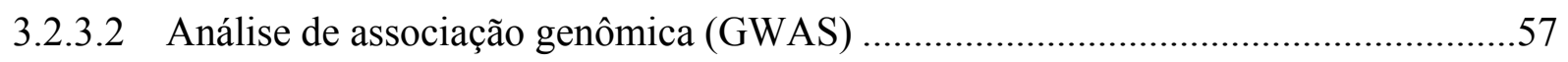

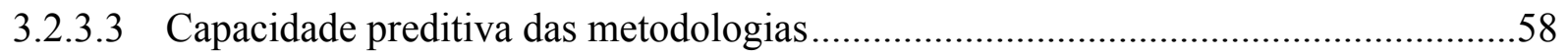

3.2.3.4 Coincidência e ganhos com a seleção .........................................................................59

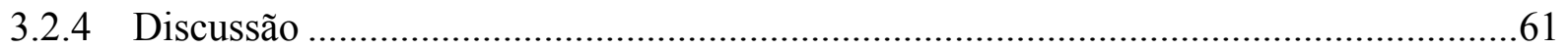

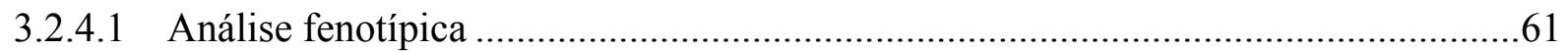

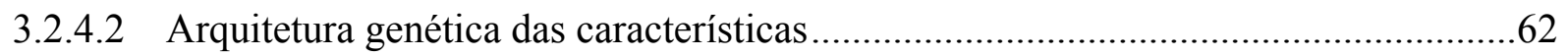

3.2.4.3 Capacidade preditiva dos métodos de GS .............................................................63

3.2.4.4 Coincidência e ganho com seleção ...........................................................................64

3.2.4.5 Considerações quanto ao uso das metodologias .....................................................65

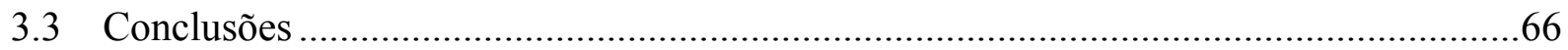


Referências. 67

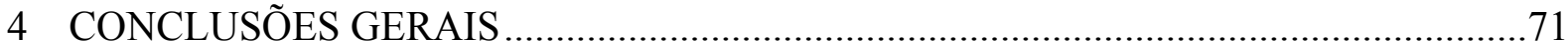




\section{RESUMO}

\section{Predição genômica de híbridos de milho para caracteres de arquitetura oligogênica e sob diferentes parâmetros de penalização e correção de fenótipo}

O alcance de altas produtividades em milho (Zea mays L.) depende do desenvolvimento de híbridos, o principal produto explorado nos programas de melhoramento. O sucesso na obtenção deste tipo de cultivar é conseguido com extensivo cruzamento de linhagens, seguido de avaliações para identificação das combinações de maior potencial. Geralmente, o melhorista tem à sua disponibilidade grande número de linhagens, possibilitando a realização de centenas a milhares de cruzamentos distintos, dos quais apenas uma pequena quantidade pode ser avaliada experimentalmente devido a limitação de tempo e recursos. Com o advento da Seleção Genômica (GS) tornou-se possível predizer o comportamento destes indivíduos não avaliados com base em seu genoma. No decorrer do processo de consolidação da GS várias metodologias foram propostas. A aptidão destas em predizer desempenhos fenotípicos é dependente da sua capacidade de acomodar a arquitetura genética das características e lidar com a multicolinearidade das matrizes genômicas. Neste sentido, métodos baseados em modelos mistos podem apresentar menor eficiência na predição de características oligogênicas devido à não capacidade de representar a distribuição real do efeito dos QTL. Além disso, a regularização das predições na presença de multicolinearidade é realizada por meio de um parâmetro de penalização $(\lambda)$, o qual pode ser estimado de várias formas e consequentemente modificar a acurácia dos modelos. Além do aprimoramento dos métodos, outro aspecto importante é o procedimento de correção dos dados fenotípicos previamente à GS, o qual não é consenso na comunidade científica. Diante do exposto, este trabalho objetivou: verificar o efeito das formas de obtenção do $\lambda$ (via REML na GS e pela herdabilidade da característica) e da correção do fenótipo (valor genotípico e média ajustada) na GS e avaliar a eficiência da modelagem diferencial de QTL de maior efeito na capacidade preditiva da metodologia G-BLUP, comparando-a ao LASSO Bayesiano, BayesB e G-BLUP convencional. Para isso foram utilizadas informações de híbridos simples de milho tropical avaliados em cinco locais para produtividade de grãos, altura de planta e espiga no ano de 2015. Os dados genômicos foram obtidos com a plataforma Affymetrix ${ }^{\circ}$ Axiom $^{\circ}$ Maize Genotyping Array de 616.201 SNPs. Foram estudados diferentes cenários de GS considerando os fatores supracitados, sendo estes comparados entre si por suas capacidades preditivas e seletivas. Os resultados obtidos indicam que a correção do fenótipo e a forma de estimação de $\lambda$ afetam a capacidade preditiva. $\mathrm{O}$ uso de valores genotípicos como correção dos fenótipos e estimação de $\lambda$ via REML apresentaram os melhores resultados. Foi também observado que a modelagem de SNPs de maior efeito como fator fixo aumenta discretamente a capacidade preditiva da metodologia G-BLUP para as características oligogênicas avaliadas (altura de planta e espiga), sendo indicado o uso do G-BLUP convencional. Complementarmente, observou-se que a GS apresentou modesta eficiência na seleção de híbridos superiores sob intensidades moderadas. Entretanto, a sua alta capacidade de selecionar sob baixa intensidade pode ser amplamente explorada nos programas de melhoramento de milho visando a seleção precoce direta. 


\section{ABSTRACT \\ Genomic prediction of maize hybrids for traits with oligogenic architecture and under distinct shrinkage factors and phenotypic correction}

The achievement of high yield in maize (Zea mays L.) relies on the development of hybrids, which is the main product of breeding programs. The success in obtaining this kind of cultivar is achieved through extensive crossing of inbred lines followed by field trials to identify the combinations with greatest potential. Generally, breeders have a large number of inbred lines on their hands, being able to perform hundreds to thousands of different crosses, of which only a small portion can be experimentally evaluated due to time and resource limitations. Genomic Selection (GS) has made it possible to predict phenotypes of unevaluated individuals based on their genome. Throughout the establishment process of GS many approaches have been proposed. The ability of these approaches at predicting phenotypic performance depends on their capacity of accommodating the genetic architecture of the traits and dealing with the multicollinearity of the genomic matrices. Hence, methods based on mixed model equations may present lower prediction efficiency for oligogenic traits due to their inability of depicting the real distribution of the QTL effects. Moreover, the prediction regularization in the presence of multicollinearity is done by a shrinkage factor $(\lambda)$, which can be estimated in a number of ways and may affect the accuracy of the models. In addition to the improvement of the models, the correction of the phenotype utilized in the predictions is also important, which is not a consensus among researchers. Based on these facts, this study aimed to assess the effect of estimation of $\lambda$ (by REML in the GS model and by the heritability of the traits) and the correction of the phenotype (genotypic value and adjusted mean) on the GS. It also targeted to evaluate the effect of differential modeling of major makers on the prediction accuracy of G-BLUP, comparing it to Bayesian LASSO, BayesB and ordinary G-BLUP. To those ends, tropical maize single-crosses evaluated at five sites for grain yield, plant and ear height in 2015 were utilized. The genomic data was obtained with the Affymetrix ${ }^{\star}$ Axiom ${ }^{\circ}$ Maize Genotyping Array of 616,201 SNPs. Distinct GS scenarios were studied considering the aforementioned factors which were compared by their prediction and selection accuracy. The results suggest that the correction of the phenotype and the way of estimation of $\lambda$ do affect prediction accuracies. The use of genotypic values as the correction of phenotypes and the estimation of $\lambda$ by REML showed best results. It was also observed that modeling major SNPs as fixed effect factors had little improvement on the prediction accuracy of G-BLUP for the oligogenic traits evaluated (plant and ear height). Thereby, ordinary G-BLUP should be the method of choice to predict these traits. Additionally, it was observed that GS presented modest efficiency for selecting superior hybrids under moderate intensities. However, its high effectiveness at selecting under low intensities might be exploited on maize breeding programs for early direct selection.

Keywords: Genomic selection; BLUE; BLUP; Prediction accuracy; Genetic architecture 


\section{INTRODUÇÃO}

\subsection{Melhoramento de híbridos de milho}

Estima-se que a produção de milho (Zea mays L.) seja de 83,3 milhões de toneladas no ano agrícola de 2015/2016, cultivadas em 15,3 milhões de hectares, representando 39,63\% do volume de grãos do país. A produção é dividida entre primeira e segunda safras, das quais se espera 28,3 e 54,9 milhões de toneladas, respectivamente. Apesar do grande volume de produção, a produtividade média ainda é baixa, cerca de $4.800 \mathrm{~kg} \mathrm{ha}^{-1}$ para primeira safra, e $5.700 \mathrm{~kg} \mathrm{ha}^{-1}$ para a segunda (ano agrícola de 2014/15) (COMPANHIA NACIONAL DE ABASTECIMENTO - CONAB, 2016). Assim, a busca por cultivares mais adaptados e produtivos, bem como a melhoria nas práticas culturais, são atividades constantes que visam a maior produtividade, sustentabilidade e segurança alimentar (DUVICK, 2005).

O alcance de altas produtividades nessa espécie é dependente do desenvolvimento de híbridos, o principal produto explorado nos programas de melhoramento. Um híbrido de alto rendimento é condicionado pela expressão da heterose, ou seja, o desempenho diferencial frente a média dos genitores (REIF; HALLAUER; MELCHINGER, 2005). Para que se tenha sucesso na obtenção deste tipo de cultivar, é necessário o extensivo cruzamento de linhagens endogâmicas com avaliações minuciosas para identificação das melhores combinações (SCHRAG et al., 2009).

Os germoplasmas de milho são comumente organizados em grupos heteróticos, entre os quais são realizados cruzamentos para obtenção de híbridos de alto vigor (REIF; HALLAUER; MELCHINGER, 2005). Geralmente, cada grupo é composto por um número grande de indivíduos, possibilitando a realização de centenas a milhares de cruzamentos distintos. Infelizmente, devido a limitação de recursos, apenas uma pequena quantidade destas combinações pode ser avaliada em experimentos a campo com várias repetições e locais, sendo de grande interesse a predição daquelas que por algum motivo não foram fenotipicamente avaliadas (SCHRAG et al., 2009).

Existem diversas metodologias de predição de híbridos de alto rendimento. A predição de genótipos não avaliados pode ser realizada com o uso de dados fenotípicos por meio de associações com o desempenho per se das linhagens genitoras, estimação das capacidades gerais e específicas de combinação e procedimentos de modelos mistos (BERNARDO, 1994; SCHRAG et al., 2009; ZHAO; METTE; REIF, 2015). O progresso genético conseguido nas ultimas décadas é a prova de que a seleção fenotípica é altamente eficiente (DUVICK, 2005). Entretanto, existem ferramentas biotecnológicas, como os marcadores moleculares, que 
podem auxiliar neste processo (BERNARDO, 1998; BERNARDO, 1994; MEUWISSEN; HAYES; GODDARD, 2001).

O uso da informação genômica na predição nos híbridos de milho tem-se mostrado eficiente e bastante promissora, inclusive para a produtividade de grãos (MASSMAN et al., 2013; PIEPHO, 2009; ZHAO; METTE; REIF, 2015), característica notoriamente afetada pelo ambiente (HALLAUER; CARENA; MIRANDA FILHO, 2010). Neste contexto, com base no padrão genômico dos indivíduos, pode-se predizer combinações que não foram obtidas ou avaliadas em dialelos e testcrosses, e também conduzir seleções em populações relacionadas (SCHRAG et al., 2009).

Espera-se que com o avanço tecnológico a predição genômica torne-se vantajosa em relação à avaliação a campo (BERNARDO, 2008). Neste sentido, o uso de marcadores moleculares em associação com tecnologias como a de duplo-haploides pode acelerar significativamente o progresso genético, levando a melhor aproveitamento dos recursos e aumento na eficiência do processo seletivo (GEIGER; GORDILLO, 2009).

\subsection{Seleção genômica no melhoramento de plantas}

Segundo Bernardo e Yu (2007) a maior acessibilidade dos programas de melhoramento a dados genômicos tem transformado a forma com que esse tipo de informação é visto e implementado. Essencialmente, a ideologia passou de "como o uso de marcadores moleculares pode aumentar progresso de melhoramento?" para "como os marcadores moleculares podem ser melhor utilizados para o progresso do melhoramento?”. Em outras palavras, o atual estado de desenvolvimento é a formulação de metodologias que façam o melhor uso destas informações em prol do progresso genético e científico da espécie.

Uma metodologia que está recebendo grande atenção dos pesquisadores e empresas ultimamente é a Seleção Genômica (GS). Essa técnica foi proposta por Meuwissen, Hayes, e Goddard (2001) como uma prática baseada no desequilíbrio de ligação entre marcadores moleculares e loci controladores de características quantitativas (QTL), visando a predição simultânea dos efeitos de marcadores genéticos dispersos pelo genoma, dispensando testes de significância. Dada a grande extensão dos genomas, a captura do efeito dos QTL é dependente de plataformas de genotipagem com grande saturação de marcadores, o que era um dos entraves da metodologia devido ao alto custo de obtenção destas informações (HAYES; GODDARD, 2010). No entanto, os avanços nos processos de genotipagem têm 
aumentado a disponibilidade de plataformas de alta resolução e reduzido o custo por data point.

Ao longo dos últimos anos, foram propostos vários métodos para realização de GS, buscando maiores ajustes estatísticos com maximização da correlação entre os valores genéticos genômicos preditos com base nos efeitos dos marcadores e os valores genotípicos/genéticos reais (DE LOS CAMPOS et al., 2009; HABIER; FERNANDO; KIZILKAYA; GARRICK, 2011; MEUWISSEN; HAYES; GODDARD, 2001; RESENDE et al., 2012; VANRADEN, 2008). Cada uma destas versões melhor se aplica a um determinado cenário (DAETWYLER et al., 2013; HAYES; GODDARD, 2010), e provavelmente muitas outras serão propostas devido ao aumento da popularidade da técnica e a grande diversidade de tipos de populações e espécies sob melhoramento.

Segundo Resende et al. (2012), um método ideal de GS deve essencialmente ser capaz de acomodar a arquitetura genética, regularizar o processo de estimação na presença de multicolinearidade e selecionar marcadores que estão em LD com a característica avaliada. $\mathrm{O}$ RR-BLUP (ridge regression - best linear unbiased predictor) e o G-BLUP (Genomic best linear unbiased predictor), por exemplo, assumem grande número de marcadores de pequeno efeito seguindo a distribuição normal, todos explicando igual proporção da variância genética. Já metodologias como o BayesA, BayesB e LASSO Bayesiano, assumem informações $a$ priori que implicam em diferentes distribuições dos efeitos e variâncias explicadas pelos marcadores (HAYES; GODDARD, 2010), o que teoricamente conduz a um melhor ajuste destas metodologias para características com QTL de efeito maior.

Com a genotipagem de alta densidade, há muitos marcadores que estão em completo ou elevado LD entre si. Assim, para lidar com a multicolinearidade da matriz de marcadores, é realizada a penalização da matriz de variâncias e covariâncias genômicas com um parâmetro $\lambda$ (shrinkage factor). Este parâmetro pode ser obtido de diversas formas e pode afetar diretamente a capacidade preditiva da seleção genômica, evidenciando a importância da sua estimação adequada (RESENDE et al., 2012; ZHAO et al., 2013).

Outro aspecto importante é que o sucesso da GS não é determinado somente pelo modelo estatístico utilizado nas estimações e predições. A efetividade das metodologias baseadas em marcadores moleculares, principalmente da GS, depende da qualidade da informação utilizada na associação da variação fenotípica e genômica (TUBEROSA, 2012), especialmente da forma com que os dados são tratados previamente à análise. Diante do exposto, com este trabalho buscou-se discutir algumas questões acerca da realização da GS 
referentes a correção do fenótipo, obtenção dos parâmetros de penalização e modelagem específica de genes de maior efeito. Foram avaliadas as implicações destes fatores na capacidade de predição e seleção de indivíduos.

\section{Referências}

BERNARDO, R. Prediction of maize single-cross performance using RFLPs and information from related hybrids. Crop Science, Madison, v. 34, n. 1, p. 20, 1994.

. A model for marker-assisted selection among single crosses with multiple genetic

markers. Theoretical and Applied Genetics, Berlin, v. 97, n. 3, p. 473-478, 1998.

. Molecular markers and selection for complex traits in plants: Learning from the last 20 years. Crop Science, Madison, v. 48, n. 5, p. 1649-1664, 2008.

BERNARDO, R.; YU, J. Prospects for genomewide selection for quantitative traits in maize. Crop Science, Madison, v. 47, n. 3, p. 1082-1090, 2007.

COMPANHIA NACIONAL DE ABASTECIMENTO. Acompanhamento de safra brasileira: grãos. v. 3: safra 2015/16 n. 5; quinto levantamento. Brasilia, 2015. 182 p.

DAETWYLER, H.D.; CALUS, M.P.L.; PONG-WONG, R.; DE LOS CAMPOS, G.; HICKEY, J.M. Genomic prediction in animals and plants: Simulation of data, validation, reporting, and benchmarking. Genetics, Austin, v. 193, n. 2, p. 347-365, 2013.

DE LOS CAMPOS, G.; NAYA, H.; GIANOLA, D.; CROSSA, J.; LEGARRA, A.; MANFREDI, E.; WEIGEL, K.; COTES, J.M. Predicting quantitative traits with regression models for dense molecular markers and pedigree. Genetics, Austin, v. 182, n. 1, p. 375-385, 2009.

DUVICK, D.N. Genetic progress in yield of United States maize (Zea mays L.). Maydica, Bergamo, v. 50, n. 3/4, p. 193-202, 2005.

GEIGER, H.H.; GORDILLO, G.A. Doubled haploids in hybrid maize breeding. Maydica, Bergamo, v. 54, n. 4, p. 485-499, 2009.

HABIER, D.; FERNANDO, R.L.; KIZILKAYA, K.; GARRICK, D.J. Extension of the bayesian alphabet for genomic selection. BMC Bioinformatics, London, v. 12, p. 186, 2011.

HALLAUER, A.R.; CARENA, M.J.; MIRANDA FILHO, J.B. Quantitative genetics in maize breeding. $3^{\text {rd }}$ ed. New York: Springer-Verlag, 2010. v. 6, 664 p.

HAYES, B.; GODDARD, M. Genome-wide association and genomic selection in animal breeding. Genome, Ottawa, v. 53, n. 11, p. 876-883, 2010. 
MASSMAN, J.M.; GORDILLO, A.; LORENZANA, R.E.; BERNARDO, R. Genomewide predictions from maize single-cross data. Theoretical and Applied Genetics, Berlin, v. 126, n. 1, p. 13-22, 2013.

MEUWISSEN, T.H.E.; HAYES, B.J.; GODDARD, M.E. Prediction of total genetic value using genome-wide dense marker maps. Genetics, Austin, v. 157, n. 4, p. 1819-1829, 2001.

PIEPHO, H.P. Ridge regression and extensions for genomewide selection in maize. Crop Science, Madison, v. 49, n. 4, p. 1165-1176, 2009.

REIF, J.C.; HALLAUER, A.R.; MELCHINGER, A.E. Heterosis and heterotic patterns in maize. Maydica, Bergamo, v. 50, n. 3/4, p. 215-223, 2005.

RESENDE, M.D.V.; SILVA, F.F.; LOPES, P.S.; AZEVEDO, C.F. Seleção genômica ampla (gws) via modelos mistos (reml/blup), inferência bayesiana $(\mathrm{mcmc})$, regressão aleatória multivariada e estatística espacial. Viçosa: Universidade Federal de Viçosa, Departamento de Estatística, 2012. 291 p.

SCHRAG, T A.; FRISCH, M.; DHILLON, B.S.; MELCHINGER, A.E. Marker-based prediction of hybrid performance in maize single-crosses involving doubled haploids. Maydica, Bergamo, v. 54, n. 2/3, p. 353-362, 2009.

TUBEROSA, R. Phenotyping for drought tolerance of crops in the genomics era. Frontiers in Physiology, Lausanne, v. 3, p. 1-26, 2012.

VANRADEN, P.M. Efficient methods to compute genomic predictions. Journal of Dairy Science, Champaign, v. 91, n. 11, p. 4414-4423, 2008.

ZHAO, Y.; METTE, M.F.; REIF, J.C. Genomic selection in hybrid breeding. Plant Breeding, Malden, v. 134, n. 1, p. 1-10, 2015.

ZHAO, Y.; GOWDA, M.; LIU, W.; WÜRSCHUM, T.; MAURER, H.P.; LONGIN, F.H.; RANC, N.; PIEPHO, H.P.; REIF, J.C. Choice of shrinkage parameter and prediction of genomic breeding values in elite maize breeding populations. Plant Breeding, Malden, v. 132, n. 1, p. 99-106, 2013. 


\title{
EFEITO dO PARÂMETRO de PENALIZAÇÃo E DA CORREÇÃo do FENÓTIPO NA PREDIÇÃO GENÔMICA DE HÍBRIDOS SIMPLES DE MILHO TROPICAL
}

\section{Resumo}

A eficiência da Seleção Genômica (GS) depende do aprimoramento dos modelos e da qualidade da informação utilizada nas predições. Uma questão importante para a realização da GS é a correção do fenótipo e, no caso da metodologia RR-BLUP, também a escolha do parâmetro de penalização (shrinkage factor). Com isto, o objetivo foi verificar o efeito da forma de estimação do parâmetro de penalização e da correção do fenótipo na capacidade preditiva e seletiva da GS em híbridos simples de milho tropical. Para tal, foram utilizados 452 híbridos simples de milho provenientes do cruzamento em dialelo parcial de 111 linhagens endogâmicas. Estes foram avaliados para altura de planta, altura de espiga e produtividade de grãos em cinco locais no ano de 2015. As linhagens genitoras foram genotipadas com a plataforma Affymetrix ${ }^{\star}$ Axiom $^{\star}$ Maize Genotyping Array de 616.201 SNPs. Os polimorfismos tiveram sua qualidade controlada pelos procedimentos de Minor Allele Frequency, Call Rate e eliminação de heterozigotos. A composição genômica dos híbridos foi obtida como a combinação direta do padrão genômico de seus genitores. Estes híbridos foram utilizados em diferentes cenários de GS compostos em sistema fatorial $2 \times 2$, considerando o fenótipo para a GS como sendo a média ajustada (natureza fixa) ou valor genotípico (natureza aleatória) e o parâmetro de penalização com estimação por REML ou pela própria herdabilidade da característica no sentido restrito. Os valores genotípicos e médias ajustadas foram obtidos por meio de equações de modelos mistos do tipo REML/BLUP. Destas também foram obtidos os componentes de variância para estimação das herdabilidades no sentido amplo e restrito. As capacidades preditivas dos cenários de GS foram estimadas por validação cruzada $(k$-fold $)$. Os fatores utilizados na formação dos cenários foram avaliados pela análise de variância. Em seguida, as médias dos fatores foram comparadas pelo teste de Tukey. Adicionalmente, os cenários foram avaliados em relação a sua capacidade de seleção de indivíduos, usando como padrão a seleção fenotípica. $O$ fator "parâmetro de penalização" não apresentou efeito sobre as capacidades preditivas para altura de planta e espiga, mas foi significativo para produtividade de grãos, sendo a estimação por REML superior. Quanto a seleção e ordenamento dos indivíduos, este fator não apresentou resultados consistentes para as três características. Por sua vez, a correção do fenótipo foi mais eficiente com o uso de valores genotípicos, tanto para a capacidade preditiva, quanto para seleção e ordenamento dos indivíduos. De forma geral, a GS sob moderada intensidade de seleção apresentou média a baixa coincidência com a seleção fenotípica. Por outro lado, a técnica mostrou-se bastante eficiente sob baixa intensidade de seleção.

Palavras-chave: Seleção genômica; RR-BLUP; BLUE; BLUP; REML; Herdabilidade

\begin{abstract}
The efficiency of Genomic Selection (GS) relies on the improvement of the models and the quality of the information utilized in the predictions. An important question on the execution of GS is how the correction of phenotypes should be done, and in the case of the RR-BLUP method, how to properly estimate the shrinkage factor. Thus, the objective of this study was to assess the effect of the choice of the shrinkage factor and the correction of the
\end{abstract}


phenotype on the prediction accuracy of GS of tropical maize hybrids. To this end, 452 maize single-crosses from partial diallel mating design of 111 inbred lines were utilized. These genotypes were evaluated for plant height, ear height and grain yield at five locations in 2015 . The parental lines were genotyped using the Affymetrix ${ }^{\circ}$ Axiom ${ }^{\circ}$ Maize Genotyping Array of 616,201 SNPs, which had their quality controlled by Minor Allele Frequency and Call Rate procedures and elimination of heterozygous loci. The genotype of the hybrids was assessed as the combination of the genomic information of their parents. GS was performed under distinct scenarios in $2 \times 2$ factorial design comprised of adjusted mean and genotypic value (phenotype corrections) and estimation of shrinkage factor by REML and by the trait's narrow-sense heritability. The genotypic value and adjusted mean were obtained by REML/BLUP mixed model equations. Variance components for narrow and broad sense heritability estimation were also obtained from these equations. The predictive accuracies of the GS scenarios were assessed by cross-validation (k-fold) scheme. The factors comprising the scenarios were evaluated by Analysis of Variance. Then, the means of the factors were compared by Tukey's test. Additionally, the scenarios were evaluated regarding their capability of selecting genotypes having the phenotypic selection as standard. The "shrinkage factor" did not show effect on the prediction accuracy of plant and ear height, but was significant for grain yield, in which REML estimation was superior. On regard of selection and rank coincidence, this factor did not exhibit consistent results across the three traits. On its turn, phenotypic correction was more efficient when genotypic values were used, yielding better predictive accuracy, selection and ranking correlations. Overall, GS presented modest to low selection coincidence with phenotypic selection under moderate selection intensity. On the other hand, this technique proved to be highly efficient at selecting hybrids of tropical maize under low selection intensity.

Keywords: Genomic selection; RR-BLUP; BLUE; BLUP; REML; Heritability

\subsection{Introdução}

O conceito inovador de predição simultânea de efeitos de marcadores associados a QTL ao nível populacional foi proposto por Meuwissen, Hayes, e Goddard (2001). Este conceito consolidou-se em uma nova ferramenta de seleção, chamada Seleção Genômica (GS) e estabeleceu novos patamares para a utilidade da informação genômica no melhoramento vegetal (BERNARDO; YU, 2007; MASSMAN et al., 2013). A aplicação desta metodologia na predição de híbridos de milho (Zea mays L.) tem-se mostrado eficiente e promissora (ZHAO; METTE; REIF, 2015).

A metodologia de GS chamada RR-BLUP (ridge regression - best linear unbiased preditction) (MEUWISSEN; HAYES; GODDARD, 2001; WHITTAKER; THOMPSON; DENHAM, 2000) tem sido bastante utilizada na predição de valores genéticos genômicos (VGG) (ZHAO; METTE; REIF, 2015). Nessa metodologia, a variância genética é dividida igualmente entre um grande número de marcas ( $\mathrm{Vg} / \mathrm{Nmarcas}$ ), a qual é uma suposição errônea adotada por conveniência (HAYES; GODDARD, 2010). Entretanto, alguns autores afirmam 
que a perda de resposta à seleção devido a essa suposição não é relevante, e a metodologia apresenta elevada eficiência (BERNARDO; YU, 2007).

A eficiência da seleção genômica é dependente da proporção da variação genética explicada pelos marcadores e da acurácia de predição dos efeitos daqueles em desequilíbrio de ligação com QTL (RESENDE et al., 2012). A predição destes efeitos é coordenada por um parâmetro de penalização $(\lambda)$ que determina a magnitude de encolhimento (shrinkage), estabilizando as estimações e evitando a superparametrização. A estimação deste parâmetro para uso no RR-BLUP pode ser realizada por meio dos componentes de variância da análise fenotípica, pelas variâncias genética e residual estimadas por máxima verossimilhança restrita (REML) na GS (ZHAO et al., 2013) e pelo uso da própria herdabilidade da característica (RESENDE et al., 2012).

Neste contexto, existem algumas situações em que a estimação dos componentes de variância por REML é inconsistente. Por exemplo, quando a superfície de verossimilhança é plana ou com múltiplos picos (YANG, 2014), levando a estimativas imprecisas do parâmetro de penalização. Assim, o uso da herdabilidade, coeficiente que representa a relação entre genótipo e fenótipo, poderia acrescentar segurança às predições da GS, desde que seja capaz de expressar a relação das variáveis genômicas (marcadores moleculares) com o fenótipo.

O avanço tecnológico das últimas décadas fez com que a obtenção da informação genômica deixasse de ser um gargalo para condução da predição baseada em marcadores moleculares. Concomitantemente, recuperou-se a atenção à qualidade da informação fenotípica empregada em sua realização. É consenso a correção do fenótipo para efeitos ambientais decorrentes da condução experimental, pois estes efeitos não são passíveis de seleção (PIEPHO et al., 2008). Entretanto, a forma de correção do fenótipo a ser utilizada na GS ainda não é uma unanimidade na comunidade científica.

Neste sentido, a obtenção do componente genético com o BLUP (Best Linear Unbiased Predictor) maximiza a correlação entre os valores genotípicos preditos e reais nas equações de modelos mistos (SEARLE; CASELLA; MCCULLOCH, 2006). O BLUE (Best Linear Unbiased Estimator), por outro lado, pode ser visto como um caso limitante do BLUP quando o fator de encolhimento tende a zero (PIEPHO et al., 2008). Mesmo assim, médias ajustadas são comumente utilizadas na GS (WÜRSCHUM et al., 2013; ZHAO et al., 2014), buscando melhorar a acurácia preditiva por meio da recuperação de informação de efeitos fixos e também evitar a dupla penalização dos VGGs. 
A qualidade e quantidade de informações fenotípicas no melhoramento vegetal, teoricamente, pode fazer com que a estimação por BLUE e BLUP conduzam a seleções semelhantes. Entretanto, em experimentos onde existe desbalanceamento genético ou estatístico e os indivíduos sejam aparentados, é esperado que as estimativas não sejam concordantes (PIEPHO et al., 2008). Assim, o objetivo deste trabalho foi também avaliar formas de correção da informação fenotípica para maior acurácia preditiva da GS em híbridos de milho tropical.

\subsection{Desenvolvimento}

\subsubsection{Objetivos}

\subsubsection{Objetivo geral}

Avaliar o efeito dos parâmetros de penalização e da correção de fenótipos na capacidade preditiva e seletiva da seleção genômica em híbridos simples de milho tropical.

\subsubsection{Objetivos específicos}

- Verificar se o uso da herdabilidade no sentido restrito para obtenção do parâmetro de penalização aumenta a capacidade preditiva de híbridos simples de milho tropical.

- Verificar se o tipo de correção do fenótipo a ser utilizado na seleção genômica modifica a capacidade preditiva de híbridos simples de milho tropical.

- Avaliar se a seleção de híbridos de milho tropical por valores genéticos genômicos é mais eficiente sob moderada ou baixa intensidade de seleção.

\subsubsection{Material e Métodos}

\subsubsection{População de treinamento e obtenção de dados fenotípicos}

Foram utilizados 452 híbridos obtidos pelo delineamento genético do tipo dialelo parcial com o uso de 111 linhagens endogâmicas. As características avaliadas foram altura de planta $(\mathrm{cm})$, altura de espiga $(\mathrm{cm})$ e produtividade de grãos $\left(\mathrm{kg} \mathrm{ha}^{-1}\right)$. As parcelas foram compostas por duas linhas de cinco metros, espaçadas $0,7 \mathrm{~m}$. A altura de planta e espiga foram avaliadas com base em uma planta representativa da parcela, sendo que a primeira foi medida do solo até a folha bandeira e a segunda do solo até a base da espiga. As mensurações de altura foram realizadas no quinto estádio reprodutivo (R5). A produtividade de grãos foi 
obtida com a colheita mecanizada de toda a parcela. Esta variável foi ajustada considerando a padronização da umidade na colheita para $13 \%$ e para estande, quando este não apresentou efeito genético significativo. Os experimentos foram conduzidos no ano agrícola de 2015 delineados em blocos casualizados com duas repetições, avaliados em Ipiaçú-MG, Patos de Minas-MG, Sertanópolis-PR, Nova Mutum-MT, e Sorriso-MT, sendo excepcionalmente altura de planta e espiga avaliadas somente nos três primeiros locais. Houve desbalanceamento estatístico e genético, pois nem todos os híbridos foram avaliados em todos os locais e nem todas as combinações híbridas entre linhagens genitoras foram analisadas. A condução experimental e obtenção dos dados genômicos das linhagens genitoras são creditados à empresa Helix Sementes Ltda..

\subsubsection{Dados genômicos}

A plataforma Affymetrix ${ }^{\star}$ Axiom $^{\star}$ Maize Genotyping Array de 616.201 marcadores SNP (Single Nucleotide Polimorphism) (UNTERSEER et al., 2014) foi a escolhida para a genotipagem das 111 linhagens que deram origem aos híbridos. O controle de qualidade foi realizado por meio de Call Rate $(\mathrm{CR})$ e da frequência do alelo secundário (Minor Allele Frequency - MAF). A CR foi realizada sobre marcadores e linhagens considerando $C R \geq$ 0,95. Os dados perdidos remanescentes nas linhagens foram imputados com o pacote Synbreed (WIMMER et al., 2012), por meio de algoritmos do software Beagle 4.0 (BROWNING; BROWNING, 2009), considerando somente a imputação de combinações homozigotas. O genótipo dos híbridos foi obtido por meio da combinação de marcadores homozigotos das respectivas linhagens genitoras. A MAF foi realizada sobre o genótipo dos híbridos, considerando frequência do alelo secundário igual ou superior 0,05 , para que o marcador fosse mantido. O procedimento de controle de qualidade foi realizado com scripts programados na linguagem $\mathrm{S}$.

\subsubsection{Cenários de GS}

Os 452 híbridos foram avaliados em diferentes cenários de seleção genômica. Neste contexto, quatro combinações foram formadas em sistema fatorial $2 \times 2$, considerando $\mathrm{o}$ fenótipo da GS como sendo a média ajustada (natureza fixa) ou valor genotípico (natureza aleatória) e o parâmetro de penalização com estimação por REML ou pela própria herdabilidade da característica. 


\subsubsection{Obtenção dos valores genotípicos e médias ajustadas}

Equações de modelos mistos foram utilizadas na análise estatística dos dados fenotípicos. A estimação dos componentes de variância e a predição dos efeitos aleatórios foi realizada por meio do método da Máxima Verossimilhança Restrita/Melhor Preditor Linear Não Viesado (REML/BLUP) (RESENDE, 2007). A significância dos fatores aleatórios foi avaliada pelo teste da razão de verossimilhança (Likelihood Ratio Test - LRT) por meio da Análise de Deviance (ANADEV), conforme descrito em Fritsche-Neto (2011) e fatores de efeito fixo foram avaliados pelo teste de Wald (GILMOUR et al., 2009). A obtenção dos componentes de variância e parâmetros genéticos foi realizada considerando o modelo representado por:

$$
\boldsymbol{y}=X \boldsymbol{r}+T \boldsymbol{g}+L \boldsymbol{a}+H \boldsymbol{x}+\boldsymbol{\varepsilon}
$$

em que, $\boldsymbol{y}$ : é o vetor de observações fenotípicas dos caracteres avaliados nos híbridos; $\boldsymbol{r}$ : é o efeito de bloco, considerado como fixo, e somado à média geral; $\boldsymbol{g}$ : vetor dos efeitos de genótipo, explicados adiante; $\boldsymbol{a}$ : vetor dos efeitos aleatórios de local, sendo $\boldsymbol{a} \sim N I D\left(0, I \sigma_{a}^{2}\right)$; $\boldsymbol{x}$ : vetor de efeitos da interação genótipo $\times$ local, considerados aleatórios, em que $\boldsymbol{x} \sim N I D\left(0, I \sigma_{g \times a}^{2}\right) ; \boldsymbol{\varepsilon}$ : é o vetor de erros, onde $\boldsymbol{\varepsilon} \sim N I D\left(0, I \sigma_{\varepsilon}^{2}\right) . X, T, L$ e $H$ são matrizes de incidência que relacionam os efeitos dos vetores independentes ao vetor dependente $\boldsymbol{y}$. Considerando a análise conjunta dos ambientes, a correção do fenótipo para obtenção do componente genético dos 452 híbridos foi realizada de duas formas diferentes com variação na pressuposição de sua natureza:

(i) Efeito genético como fixo: a média ajustada foi obtida por meio do melhor estimador linear não viesado (BLUE).

(ii) Efeito genético como aleatório: os valores genotípicos dos híbridos foram preditos pelo melhor preditor linear não viesado (BLUP), onde $\boldsymbol{g} \sim N I D\left(0, I \sigma_{g}^{2}\right)$.

A herdabilidade no sentido amplo foi estimada ao nível de indivíduo $\left(h_{g i}^{2}\right)$ e médias de locais $\left(h_{g m}^{2}\right)$ com base nos componentes estimados no caso (ii) por meio de:

$$
h_{g i}^{2}=\frac{\sigma_{g}^{2}}{\left(\sigma_{g}^{2}+\sigma_{g \times a}^{2}+\sigma_{\varepsilon}^{2}\right)} \text { e } h_{g m}^{2}=\frac{\sigma_{g}^{2}}{\left(\sigma_{g}^{2}+\frac{\sigma_{g \times a}^{2}}{l}+\frac{\sigma_{\varepsilon}^{2}}{r l}\right)}
$$


em que $\sigma_{g}^{2}$ é a variância genotípica, $\sigma_{g \times a}^{2}$ é a variância da interação genótipo $\times$ local, $\sigma_{\varepsilon}^{2}$ é a variância residual, $r$ é o número de repetições e $l$ é o número de locais. A herdabilidade no sentido restrito $\left(h_{a}^{2}\right)$ foi estimada de forma semelhante, porém considerando o pedigree entre os híbridos com o intuito de obtenção do parâmetro de penalização para a análise genômica.

A acurácia experimental foi estimada por:

$$
\hat{r}_{g g}=\left[1-\frac{1}{1+r l . C V_{R}^{2}}\right]^{1 / 2}
$$

em que $C V_{R}=\frac{C V_{g}}{C V_{\varepsilon}}$ é o coeficiente de variação relativa, considerando o coeficiente de variação genotípica $C V_{g}=\left(\sqrt{\sigma_{g}^{2}} / \mu\right) \times 100$ e o coeficiente de variação residual $C V_{\varepsilon}=\left(\sqrt{\sigma_{\varepsilon}^{2}} / \mu\right) \times 100$; $\mu$ é a média geral da característica, $\sigma_{g}^{2}$ é a variância genotípica e $\sigma_{\varepsilon}^{2}$ é a variância residual (RESENDE; DUARTE, 2007).

O pacote ASReml-R (GILMOUR et al., 2009) do software R (R CORE TEAM, 2014) foi utilizado na implementação dos modelos considerados. As médias ajustadas e valores genotípicos foram utilizados como variável dependente $(y)$ para avaliação das metodologias de seleção genômica discutidas a seguir.

\subsubsection{Seleção genômica}

A predição dos efeitos dos marcadores na população de estimação foi realizada via metodologia de regressão aleatória do tipo RR-BLUP, aplicada à Seleção Genômica (RRBLUP/GS), segundo o modelo misto aditivo:

$$
\boldsymbol{y}=X \mu+Z \boldsymbol{a}+\boldsymbol{\varepsilon}
$$

em que, $\boldsymbol{y}$ : é o vetor de média ajustada/valor genotípico dos híbridos obtidos na análise conjunta sem pedigree; $\mu$ : é o vetor de efeitos fixos, $\boldsymbol{a}$ : é o vetor dos efeitos de marcadores, considerados aleatórios onde $\boldsymbol{a} \sim N I D(0, G)$; $\boldsymbol{\varepsilon}$ : é o vetor de erros considerando $\boldsymbol{\varepsilon} \sim N I D\left(0, R=I \sigma_{\varepsilon}^{2}\right) . X$ e $Z$ são as matrizes de incidência para $\mu$ e $\boldsymbol{a}$. A matriz $Z$ foi codificada por valores $-1,0$ e 1 , sendo -1 e 1 os homozigotos e 0 o heterozigoto. A estrutura de médias e variâncias foi definida como:

$$
E(\boldsymbol{y})=X \mu, \operatorname{Var}(\boldsymbol{y})=V=Z G Z^{\prime}+R \text { e } G=I \sigma_{a}^{2} / n .
$$


O modelo linear misto para predição de $\boldsymbol{a}$ e $\mu$ equivale a:

$$
\left[\begin{array}{cc}
X^{\prime} X & X^{\prime} Z \\
Z^{\prime} X & Z^{\prime} Z+I \lambda
\end{array}\right]\left[\begin{array}{l}
\hat{\mu} \\
\widehat{\boldsymbol{a}}
\end{array}\right]=\left[\begin{array}{c}
X^{\prime} \boldsymbol{y} \\
Z^{\prime} \boldsymbol{y}
\end{array}\right]
$$

com: $\lambda=\sigma_{\varepsilon}^{2} / \sigma_{a_{m}}^{2}$ ou $\lambda=n\left(1-h_{a}^{2}\right) / h_{a}^{2}$

em que, $\sigma_{a_{m}}^{2}$ : é a variância genética aditiva de cada marcador molecular; $\sigma_{\varepsilon}^{2}$ : é a variância residual; $n$ : número de locos controlando o caráter, dado aproximadamente por $n=$ [2 $\sum_{i}^{n} p_{i}\left(1-p_{i}\right)$ ], em que $p_{i}$ é a frequência do alelo $i$ e; $h_{a}^{2}$ é aqui considerada como a herdabilidade no sentido restrito a nível de médias de locais. Foi considerado a priori que cada loco explica $\frac{1}{n} \sigma_{a}^{2}$, o que retrata a distribuição igualitária das variâncias.

A predição do efeito das marcas $(\widehat{\boldsymbol{a}})$ foi realizada de duas formas:

(i) Com obtenção de $\lambda$ a partir dos valores de $\sigma_{a m}^{2}$ e $\sigma_{\varepsilon}^{2}$ estimados pelo método de máxima verossimilhança restrita na GS (método RR-BLUP $[\lambda \mathrm{L}]$ ).

(ii) Com utilização da herdabilidade no sentido restrito a nível de médias de locais $\left(h_{a}^{2}\right)$ para a estimação de $\lambda$ (método RR-BLUP $[\lambda F]$ ). Neste caso não foi realizada a reestimativa dos componentes de variância na seleção genômica.

As metodologias de predição do efeito das marcas foram implementadas com o pacote rrBLUP versão 4.3 (ENDELMAN, 2011) por meio da função “mixed.solve", sendo que para a metodologia RR-BLUP $[\lambda F]$ a função foi modificada para uso do $\lambda$ estimado com a herdabilidade fornecida. Os valores genéticos genômicos dos híbridos foram preditos por $V G G=\widehat{\boldsymbol{g}}=Z \widehat{\boldsymbol{a}}$ para cada uma das metodologias.

\subsubsection{Comparação dos cenários de GS}

Foi avaliada a capacidade preditiva dos diferentes cenários de GS considerados, sendo estes formados pela combinação do uso de diferentes variáveis dependentes (média ajustada e valor genotípico) e formas de estimação do parâmetro de penalização (RR-BLUP[ $\lambda \mathrm{L}]$ e RR$\operatorname{BLUP}[\lambda \mathrm{F}])$ para as três características descritas anteriormente. Para tal, foi utilizado o esquema $k$-fold de validação cruzada com distribuição aleatória dos indivíduos em dez grupos, os quais foram alocados em duas populações, uma de treinamento e outra de validação. A população de validação foi composta por um dos grupos, o qual teve seu VGG estimado com base no efeito das marcas predito nos outros nove grupos que compunham a população de treinamento. A capacidade preditiva foi obtida como a correlação de Pearson entre o VGG 
dos indivíduos e os valores de $\boldsymbol{y}$ (médias ajustadas ou valores genotípicos) correspondentes. Todos os grupos foram utilizados como população de validação, sendo seus indivíduos preditos com base no efeito das marcas estimados nos demais. Foi estimada a média da capacidade preditiva dos dez grupos, compondo a capacidade preditiva média da amostragem. O procedimento descrito acima foi realizado com 200 amostragens para formação dos grupos. Com isto, a capacidade preditiva média $\left(r_{y g}\right)$ foi estimada pela média das 200 repetições (reamostragens) para cada cenário.

A avaliação da capacidade preditiva dos diferentes cenários para cada uma das três características foi realizada por meio da análise de variância (ANAVA), considerando cada uma das 200 amostragens da validação cruzada como uma repetição. Assim, as variáveis explicativas da capacidade preditiva foram o vetor fenotípico usado na GS (média ajustada e valor genotípico) e a forma de estimação do parâmetro de penalização. $\mathrm{O}$ teste $\mathrm{F}$ foi utilizado para verificação de diferenças estatísticas significativas dos fatores avaliados. Adicionalmente, as capacidades preditivas dos fatores foram comparadas pelo teste de Tukey.

Foi também realizada a seleção dos indivíduos sob moderada $(10 \%)$ e baixa $(50 \%)$ intensidade em cada cenário de seleção fenotípica e genômica e avaliadas as coincidências de seleção entre métodos. Para a produtividade de grãos foram selecionados os indivíduos com maior valor e para a altura de planta e altura de espiga os com menor valor. Também foi obtido o coeficiente de correlação de postos de Spearman. Para a obtenção das coincidências de seleção e coeficientes de correlação de postos foi utilizado o esquema de validação independente, considerando a divisão dos indivíduos em cinco grupos.

\subsubsection{Resultados}

\subsubsection{Análise de Deviance e estimativa dos parâmetros genéticos}

Foi observada homogeneidade dos componentes de variância residuais dos experimentos realizados nas cinco estações experimentais. Os resultados da análise de Deviance conjunta indicam haver variabilidade genética entre os híbridos para as três características avaliadas (Tabela 1). Houve também diferença significativa quanto ao fator Local e quanto à interação Genótipo $\times$ Local, sugerindo comportamento diferencial dos híbridos nos diferentes locais para as características em questão. O fator Repetição foi avaliado como fixo pela estatística $\mathrm{F}$ de Wald e foi não significativo. 
Tabela 1 - Teste de Wald para os efeitos fixos e teste da razão de verossimilhança (LRT) para os efeitos aleatórios estimados via REML/BLUP para altura de planta, altura de espiga e produtividade de grãos em híbridos de milho tropical

\begin{tabular}{|c|c|c|c|}
\hline Fonte de variação & \multirow[t]{2}{*}{ Altura de planta ${ }^{\mathrm{T}}$} & \multirow[t]{2}{*}{ Altura de espiga $^{\mathrm{T}}$} & \multirow[t]{2}{*}{ Produtividade ${ }^{\mathrm{C}}$} \\
\hline Fixo $^{\mathrm{F}}$ & & & \\
\hline Repetição & $1,90^{\mathrm{NS}}$ & $1,30^{\mathrm{NS}}$ & $0,01^{\mathrm{NS}}$ \\
\hline \multicolumn{4}{|l|}{ Aleatório ${ }^{\mathrm{R}}$} \\
\hline Local & $354,91 * * *$ & $362,50 * * *$ & $1229,47 * * *$ \\
\hline Genótipo & $541,79 * * *$ & $492,26 * * *$ & $306,09 * * *$ \\
\hline Genótipo $\times$ Local & $117,48 * * *$ & $108,29 * * *$ & $406,96 * * *$ \\
\hline
\end{tabular}

Significativo a ${ }^{* * *} P=0,001$ por LRT ou $\mathrm{F}$ de Wald; ${ }^{\mathrm{NS}}$ - não significativo;

$\mathrm{F}$ - valores avaliados pelo $\mathrm{F}$ de Wald; ${ }^{\mathrm{R}}$ - valores avaliados pelo teste $\chi^{2}$ com um grau de liberdade

${ }^{\mathrm{T}}$ - avaliado em três locais; ${ }^{\mathrm{C}}$ - avaliado em cinco locais;

As herdabilidades individuais no sentido amplo foram de média magnitude para altura de planta $(0,63)$ e altura de espiga $(0,58)$ e média a baixa magnitude para a produtividade de grãos $(0,34)$. Já as herdabilidades no sentido amplo a nível de médias de locais apresentaram magnitude média a alta para estas características $(0,89,0,87$ e 0,78 , respectivamente). Os coeficientes de variação experimental foram baixos para altura de planta $(3,84 \%)$ e altura de espiga $(6,19 \%)$ e médios para a produtividade de grãos (12,42\%) (PIMENTEL-GOMES, 2009). A grandeza da variabilidade da população, representada pelo $C V_{g} \%$, foi maior para a produtividade de grãos e menor para a altura de planta. Segundo escala de Resende e Duarte (2007) as acurácias $\left(\hat{r}_{g g}\right)$ obtidas da análise de médias de locais foram muito altas para as três características.

Tabela 2 - Valores da herdabilidade no sentido amplo a nível de indivíduos $\left(h_{g i}^{2}\right)$ e médias de locais $\left(h_{g m}^{2}\right)$, média $(\bar{x})$, coeficientes de variação genético $\left(C V_{g} \%\right)$ e residual $\left(C V_{\varepsilon} \%\right)$, acurácia seletiva $\left(\hat{r}_{g g}\right)$ para altura de planta, altura de espiga e produtividade de grãos avaliados em híbridos milho tropical

\begin{tabular}{lccc}
\hline Parâmetro & Altura de planta $(\mathrm{cm})^{\mathrm{T}}$ & Altura de espiga $(\mathrm{cm})^{\mathrm{T}}$ & Produtividade $\left(\mathrm{kg} \mathrm{ha}^{-1}\right)^{\mathrm{C}}$ \\
\hline$h_{g i}^{2}$ & 0,63 & 0,58 & 0,34 \\
$h_{g m}^{2}$ & 0,89 & 0,87 & 0,78 \\
\hline $\bar{x}$ & 241,25 & 129,55 & 7380,15 \\
\hline$C V_{g} \%$ & 6,04 & 8,30 & 12,51 \\
$C V_{\varepsilon} \%$ & 3,84 & 6,19 & 12,42 \\
\hline$\hat{r}_{g g}$ & 0,97 & 0,95 & 0,95 \\
\hline${ }^{1}-$ avaliado em três locais; ${ }^{\mathrm{C}}$ - avaliado em cinco locais; & &
\end{tabular}

\subsubsection{Parâmetros da análise genômica}

O controle de qualidade dos marcadores moleculares realizado sobre linhagens genitoras e híbridos reduziu consideravelmente seu número. Aproximadamente $79 \%$ dos 
marcadores foram eliminados por serem heterozigóticos nas linhagens. Destes marcadores, menos de $1 \%$ foram eliminados por não apresentarem $\mathrm{CR} \geq 95 \%$, enquanto que nenhum indivíduo foi eliminado por este critério. Cerca de $0,26 \%$ dos dados foram imputados para complementar o genótipo das linhagens, os quais foram usados para formação do genótipo dos híbridos. O critério de MAF, realizado sobre o genótipo dos híbridos, reduziu o número de marcadores em 58,4\%. Foram também eliminados os marcadores duplicados $(42,3 \%)$. Com isto, após todo o processo de controle de qualidade, a quantidade de marcadores passou de 616.201 a 30.471, os quais foram utilizados para a seleção genômica.

A herdabilidade no sentido restrito a nível de média de locais, estimada com uso do pedigree da população foi 0,74 para altura de plantas, 0,70 para altura de espiga e 0,63 para a produtividade de grãos (Tabela 3). Estas herdabilidades foram utilizadas para a estimação do parâmetro de penalização $(\lambda)$ que realiza a penalização sobre a matriz de variância e covariância dos marcadores na metodologia RR-BLUP $[\lambda F]$ de GS. A produtividade de grãos, característica de menor herdabilidade, foi a que apresentou maior parâmetro de penalização.

Tabela 3 - Parâmetros de penalização $(\lambda)$, herdabilidade no sentido restrito a nível de médias de locais $\left(h_{a}^{2}\right)$ e herdabilidade molecular da seleção genômica $\left(h_{m}^{2}\right)$ para altura de planta (AP) e espiga (AE) e produtividade de grãos (PG), considerando a variável dependente como sendo média ajustada ou valor genotípico de híbridos de milho tropical

\begin{tabular}{lcccccc}
\hline \multirow{2}{*}{ Caráter } & \multirow{2}{*}{ RR-BLUP $[\lambda \mathrm{F}]$} & \multicolumn{4}{c}{ RR-BLUP $[\lambda \mathrm{L}]^{\text {REML }}$} \\
\cline { 2 - 7 } & $\lambda^{\mathrm{H}}$ & $h_{a}^{2}$ & $\lambda$ & $h_{m}^{2}$ & $\lambda$ & $h_{m}^{2}$ \\
\cline { 2 - 7 } & 3151,73 & 0,74 & 2417,92 & 0,79 & 2551,85 & 0,78 \\
AP & 3755,01 & 0,70 & 2540,31 & 0,78 & 2567,29 & 0,78 \\
PE & 5184,33 & 0,63 & 13868,11 & 0,39 & 13892,94 & 0,39 \\
\hline
\end{tabular}

${ }^{\mathrm{H}}$ - estimado com base na herdabilidade no sentido restrito a nível de médias de locais;

REML - componentes estimados com máxima verossimilhança restrita (REML) na GS

Para a metodologia de seleção genômica RR-BLUP $[\lambda L]$, o parâmetro de penalização foi estimado com os componentes de variância obtidos na GS. Estes componentes diferiram quando estimados com o uso de médias ajustadas e valores genotípicos na GS (dados não mostrados), mas resultaram em parâmetros de penalização e herdabilidades moleculares $\left(h_{m}^{2}\right)$ semelhantes. Entretanto, observa-se que o parâmetro $\lambda$ foi ligeiramente maior quando a média ajustada foi utilizada como variável dependente.

Altura de planta e altura de espiga apresentaram herdabilidades moleculares maiores que a herdabilidade fenotípica no sentido restrito a nível de média de locais. Para a produtividade de grãos a herdabilidade fenotípica foi maior que a molecular. 


\subsubsection{Capacidade preditiva da GS}

Os resultados obtidos na validação cruzada dos cenários de seleção genômica foram utilizados para a avaliação dos efeitos das variáveis "correção do fenótipo" (valor genotípico e médias ajustadas) e "parâmetro de penalização" (RR-BLUP[ $\lambda F]$ e RR-BLUP[ $\lambda L]$ ) (Tabela 4). Houve diferença significativa quanto ao uso de médias ajustadas e valores genotípicos para as três características em avaliação. Quanto ao parâmetro de penalização, não houve diferença significativa para altura de planta ou altura de espiga, mas houve para a produtividade de grãos.

Tabela 4 - Resumo da análise de variância para os efeitos dos parâmetros de penalização (RR-BLUP[ $\lambda F]$ e RRBLUP $[\lambda \mathrm{L}]$ ) e correção do fenótipo (média ajustada ou valor genotípico) considerando altura de plantas, altura de espiga e produtividade de grãos em híbridos de milho tropical

\begin{tabular}{lccc}
\hline \multicolumn{1}{c}{ Fonte de variação } & Altura de planta & Altura de espiga & Produtividade \\
\hline Correção do fenótipo & $128,29^{* * *}$ & $23,74^{* * *}$ & $85,60^{* * *}$ \\
Parâmetro de penalização & $2,54^{\mathrm{NS}}$ & $3,53^{\mathrm{NS}}$ & $9,15^{* *}$ \\
\hline
\end{tabular}

Significativo $0,001\left({ }^{* * *}\right), 0,01\left({ }^{* *}\right), 0,05(*)$ de probabilidade e não significativo ${ }^{(\mathrm{NS}}$ ) pelo teste $\mathrm{F}$

As capacidades preditivas variaram de 0,80 a 0,81 para altura de plantas, de 0,79 a 0,80 para altura de espigas e de 0,56 a 0,57 para produtividade (Tabela 5). Apesar das diferenças significativas proporcionadas pela correção do genótipo (e do parâmetro de penalização no caso da produtividade de grãos) as capacidades preditivas nos cenários foram relativamente constantes dentro de cada característica.

Tabela 5 - Capacidade preditiva $\left(r_{y g}\right)$ da seleção genômica considerando a estimação do parâmetro de penalização por REML (RR-BLUP $[\lambda \mathrm{L}]$ ) e pela herdabilidade (RR-BLUP $[\lambda F]$ ), com o uso de médias ajustadas ou valores genotípicos como variável dependente para altura de plantas, altura de espiga e produtividade de grãos em híbridos de milho tropical

\begin{tabular}{|c|c|c|c|}
\hline Característica & Variável dependente & Penalização & $r_{y g}{ }^{1}$ \\
\hline \multirow{4}{*}{ Altura de planta } & \multirow{2}{*}{ Média ajustada } & RR-BLUP $[\lambda F]$ & 0,80 \\
\hline & & RR-BLUP $[\lambda L]$ & 0,80 \\
\hline & \multirow{2}{*}{ Valor genotípico } & RR-BLUP $[\lambda F]$ & 0,81 \\
\hline & & RR-BLUP $[\lambda L]$ & 0,81 \\
\hline \multirow{4}{*}{ Altura de espiga } & \multirow{2}{*}{ Média ajustada } & RR-BLUP $[\lambda F]$ & 0,79 \\
\hline & & RR-BLUP $[\lambda L]$ & 0,79 \\
\hline & \multirow{2}{*}{ Valor genotípico } & RR-BLUP $[\lambda F]$ & 0,79 \\
\hline & & RR-BLUP $[\lambda L]$ & 0,80 \\
\hline \multirow{4}{*}{ Produtividade } & \multirow{2}{*}{ Média ajustada } & RR-BLUP $[\lambda F]$ & 0,56 \\
\hline & & RR-BLUP $[\lambda L]$ & 0,56 \\
\hline & \multirow{2}{*}{ Valor genotípico } & RR-BLUP $[\lambda F]$ & 0,57 \\
\hline & & RR-BLUP $[\lambda L]$ & 0,57 \\
\hline
\end{tabular}

- média de 200 reamostragens 
A comparação das médias de cada fator mostrou que o uso de valor genotípico como variável dependente na GS conduz a capacidades preditivas mais altas para todas as características (Tabela 6). Quanto ao método de estimação do parâmetro de penalização, não houve diferença entre as capacidades preditivas para a altura de planta e altura de espiga. No caso da produtividade de grãos, a metodologia RR-BLUP $[\lambda \mathrm{L}]$ foi a que apresentou melhor resultado.

Tabela 6 - Teste de comparação de médias de Tukey para capacidades preditivas considerando valores genotípicos e médias ajustadas, e métodos de estimação do parâmetro de penalização (herdabilidade e REML), para produtividade de grãos, altura de planta e altura de espiga em híbridos de milho tropical

\begin{tabular}{|c|c|c|c|}
\hline Fator & Altura de planta* & Altura de espiga* & Produtividade de Grãos* \\
\hline Valor genotípico & $0,81^{\mathrm{A}}$ & $0,80^{\mathrm{A}}$ & $0,57^{\mathrm{A}}$ \\
\hline Média ajustada & $0,80^{\mathrm{B}}$ & $0,79^{\mathrm{B}}$ & $0,56^{\mathrm{B}}$ \\
\hline RR-BLUP $[\lambda \mathrm{L}]$ & $0,81^{\mathrm{A}}$ & $0,79^{\mathrm{A}}$ & $0,57^{\mathrm{A}}$ \\
\hline RR-BLUP $[\lambda F]$ & $0,80^{\mathrm{A}}$ & $0,79^{\mathrm{A}}$ & $0,56^{\mathrm{B}}$ \\
\hline
\end{tabular}

* - médias seguidas pela mesma letra na coluna não diferem entre si a 5\% de significância pelo teste de Tukey

\subsubsection{Ordenamento, seleção de genótipos}

Os coeficientes de correlação de postos de Spearman foram estimados entre os valores genotípicos, médias ajustadas e VGGs dos indivíduos (Tabela 7). Houve grande correspondência de ordenamentos entre cenários de GS dentro de cada uma das três características avaliadas. Entretanto, estes coeficientes foram menores para a produtividade de grãos. A correlação entre os ordenamentos dos VGGs (todos os cenários de GS) e os ordenamentos fenotípicos (média ajustada e valor genotípico) foi de aproximadamente 0,78 para altura de plantas e altura de espiga. A produtividade de grãos foi a característica que apresentou a menor correlação entre os ordenamentos genômicos e fenotípicos (aproximadamente 0,58). Já as correlações de ordenamento entre médias ajustadas e valores genotípicos da análise fenotípica foram acima de 0,99 .

Fixando o tipo de correção do fenótipo e variando o parâmetro de penalização, as metodologias (RR-BLUP $[\lambda \mathrm{L}]$ e RR-BLUP $[\lambda F]$ ) proporcionaram ordenamentos semelhantes com a seleção fenotípica. Por sua vez, fixando o parâmetro de penalização, foi observado que a correlação de Spearman entre valores genotípicos e VGGs estimados com valores genotípicos foi maior do que a correlação das médias ajustadas com os VGGs estimados com médias ajustadas no caso da altura de espiga e produtividade de grãos. 
Tabela 7 - Coeficientes de correlação de postos de Spearman para valores genotípicos (VG) e médias ajustadas (MA) obtidas na análise fenotípica e valores genéticos genômicos preditos com uso do parâmetro de penalização estimado pela herdabilidade (RR-BLUP[ $\lambda F]$ ) e por REML (RR-BLUP[ $\lambda \mathrm{L}]$ ), considerando o uso de médias ajustadas ou valores genotípicos como variável dependente na seleção genômica para altura de plantas, altura de espiga e produtividade de grãos

\begin{tabular}{|c|c|c|c|c|c|c|c|}
\hline \multicolumn{8}{|c|}{ Altura de planta } \\
\hline & & \multicolumn{3}{|c|}{ Média ajustada } & \multicolumn{3}{|c|}{ Valor genotípico } \\
\hline & & RR-BLUP[F] & RR-BLUP $[\lambda L]$ & Fenótipo $^{+}$ & RR-BLUP $[\lambda F]$ & RR-BLUP $[\lambda L]$ & Fenótipo $^{\S}$ \\
\hline \multirow{3}{*}{ MA } & RR-BLUP $[\lambda F]$ & - & $1,00^{\mathrm{D}}$ & 0,78 & 1,00 & 1,00 & 0,78 \\
\hline & RR-BLUP $[\lambda L]$ & & - & 0,78 & 1,00 & 1,00 & 0,78 \\
\hline & Fenótipo $^{+}$ & & & - & 0,78 & 0,78 & 1,00 \\
\hline \multirow{3}{*}{ VG } & RR-BLUP $[\lambda F]$ & & & & - & 1,00 & 0,78 \\
\hline & RR-BLUP $[\lambda \mathrm{L}]$ & & & & & - & 0,78 \\
\hline & Fenótipo $^{\S}$ & & & & & & - \\
\hline
\end{tabular}

\begin{tabular}{|c|c|c|c|c|c|c|c|}
\hline \multicolumn{8}{|c|}{ Altura de espiga } \\
\hline & & \multicolumn{3}{|c|}{ Média ajustada } & \multicolumn{3}{|c|}{ Valor genotípico } \\
\hline & & RR-BLUP $[\lambda F]$ & RR-BLUP $[\lambda L]$ & Fenótipo & RR-BLUP $[\lambda F]$ & RR-BLUP $[\lambda L]$ & Fenótipo \\
\hline \multirow{3}{*}{ MA } & RR-BLUP $[\lambda F]$ & - & 1,00 & 0,77 & 1,00 & 1,00 & 0,78 \\
\hline & RR-BLUP $[\lambda L]$ & & - & 0,77 & 1,00 & 1,00 & 0,78 \\
\hline & Fenótipo & & & - & 0,78 & 0,78 & 1,00 \\
\hline \multirow{3}{*}{$\mathrm{VG}$} & RR-BLUP[ $\lambda F]$ & & & & - & 1,00 & 0,78 \\
\hline & RR-BLUP $[\lambda L]$ & & & & & - & 0,78 \\
\hline & Fenótipo & & & & & & - \\
\hline
\end{tabular}

\begin{tabular}{|c|c|c|c|c|c|c|c|}
\hline \multicolumn{8}{|c|}{ Produtividade de grãos } \\
\hline & & \multicolumn{3}{|c|}{ Média ajustada } & \multicolumn{3}{|c|}{ Valor genotípico } \\
\hline & & RR-BLUP $[\lambda F]$ & RR-BLUP $[\lambda L]$ & Fenótipo & RR-BLUP $[\lambda F]$ & RR-BLUP $[\lambda L]$ & Fenótipo \\
\hline \multirow{3}{*}{ MA } & RR-BLUP $[\lambda F]$ & - & 0,99 & 0,57 & 0,99 & 0,97 & 0,57 \\
\hline & RR-BLUP $[\lambda L]$ & & - & 0,57 & 0,97 & 0,98 & 0,57 \\
\hline & Fenótipo & & & - & 0,58 & 0,58 & 0,99 \\
\hline \multirow{3}{*}{ VG } & RR-BLUP $[\lambda F]$ & & & & - & 0,98 & 0,58 \\
\hline & RR-BLUP $[\lambda L]$ & & & & & - & 0,58 \\
\hline & Fenótipo & & & & & & - \\
\hline
\end{tabular}

${ }^{+}$- média ajustada obtida na seleção fenotípica

$\S$ - valor genotípico obtido na seleção fenotípica

D - valores ajustados para duas casas decimais

Um dos pontos mais importantes do melhoramento é a identificação de materiais superiores. Para tal foi estimada a coincidência entre conjuntos de $11(10 \%)$ indivíduos que teriam sido selecionados com base em seus valores genotípicos, médias ajustadas e VGGs (de todos os cenários de GS) (Tabela 8 - diagonal superior). Foi observada grande coincidência de indivíduos selecionados nos cenários de GS para as três características (93 a 98\%). A coincidência entre a GS e a seleção fenotípica (selecionados pela média ajustada ou valor genotípico) variou de 64 a $65 \%$ para altura de planta, de 58 a $60 \%$ para altura de espiga e de 21 a $25 \%$ para a produtividade de grãos.

Apesar da capacidade similar das metodologias de GS (RR-BLUP[F] e RR-BLUP[L]) em selecionar indivíduos superiores quando comparadas à seleção fenotípica, a RR-BLUP[L] 
foi superior para a produtividade de grãos e RR-BLUP[F] para altura de plantas e altura de espiga em pelo menos um dos tipos de variável dependente. A coincidência de seleção entre valores genotípicos e VGGs estimados com valores genotípicos foi maior do que a coincidência das médias ajustadas com os VGGs estimados com médias ajustadas, exceto para a altura de espiga (para cada uma das metodologias de GS). A coincidência de indivíduos selecionados por médias ajustadas e valores genotípicos foi de $97 \%$ para a altura de planta, $96 \%$ para altura de espiga, e $86 \%$ para a produtividade de grãos.

Tabela 8 - Coincidência de seleção dos 10\% (diagonal superior) e 50\% (diagonal inferior) melhores híbridos com base em valores genotípicos (VG), médias ajustadas (MA) e valores genéticos genômicos preditos com uso do parâmetro de penalização estimado pela herdabilidade (RR-BLUP[ $\lambda F]$ ) e por REML (RR-BLUP $[\lambda \mathrm{L}]$ ), considerando o uso de médias ajustadas ou valores genotípicos como variável dependente na seleção genômica para altura de plantas, altura de espiga e produtividade de grãos

\begin{tabular}{|c|c|c|c|c|c|c|c|}
\hline \multicolumn{8}{|c|}{ Altura de planta } \\
\hline & & \multicolumn{3}{|c|}{ Média ajustada } & \multicolumn{3}{|c|}{ Valor genotípico } \\
\hline & & RR-BLUP $[\lambda F]$ & RR-BLUP $[\lambda L]$ & Fenótipo $^{+}$ & RR-BLUP $[\lambda F]$ & RR-BLUP $[\lambda L]$ & Fenótipo $^{\S}$ \\
\hline \multirow{3}{*}{ MA } & RR-BLUP $[\lambda F]$ & - & $98 \%$ & $64 \%$ & $97 \%$ & $95 \%$ & $65 \%$ \\
\hline & RR-BLUP $[\lambda L]$ & $99 \%$ & - & $64 \%$ & $97 \%$ & $97 \%$ & $64 \%$ \\
\hline & Fenótipo $^{+}$ & $78 \%$ & $78 \%$ & - & $64 \%$ & $64 \%$ & $97 \%$ \\
\hline \multirow{3}{*}{ VG } & RR-BLUP $[\lambda F]$ & $98 \%$ & $98 \%$ & $78 \%$ & - & $97 \%$ & $65 \%$ \\
\hline & RR-BLUP $[\lambda L]$ & $98 \%$ & $98 \%$ & $78 \%$ & $99 \%$ & - & $64 \%$ \\
\hline & Fenótipo $^{\S}$ & $78 \%$ & $78 \%$ & $99 \%$ & $78 \%$ & $78 \%$ & - \\
\hline
\end{tabular}

Altura de espiga

\begin{tabular}{|c|c|c|c|c|c|c|c|}
\hline & & \multicolumn{3}{|c|}{ Média ajustada } & \multicolumn{3}{|c|}{ Valor genotípico } \\
\hline & & RR-BLUP $[\lambda F]$ & RR-BLUP[ $\lambda \mathrm{L}]$ & Fenótipo & RR-BLUP $[\lambda F]$ & RR-BLUP[ $\lambda \mathrm{L}]$ & Fenótipo \\
\hline & RR-BLUP $[\lambda F]$ & - & $96 \%$ & $60 \%$ & $96 \%$ & $95 \%$ & $59 \%$ \\
\hline \multirow[t]{3}{*}{ MA } & RR-BLUP $[\lambda L]$ & $98 \%$ & - & $60 \%$ & $95 \%$ & $96 \%$ & $59 \%$ \\
\hline & Fenótipo & $81 \%$ & $80 \%$ & - & $59 \%$ & $59 \%$ & $96 \%$ \\
\hline & RR-BLUP $[\lambda F]$ & $98 \%$ & $98 \%$ & $81 \%$ & - & $97 \%$ & $59 \%$ \\
\hline \multirow[t]{2}{*}{ VG } & RR-BLUP $[\lambda L]$ & $98 \%$ & $98 \%$ & $80 \%$ & $98 \%$ & - & $58 \%$ \\
\hline & Fenótipo & $81 \%$ & $81 \%$ & $98 \%$ & $81 \%$ & $81 \%$ & - \\
\hline \multicolumn{8}{|c|}{ Produtividade de grãos } \\
\hline & & \multicolumn{3}{|c|}{ Média ajustada } & \multicolumn{3}{|c|}{ Valor genotípico } \\
\hline & & RR-BLUP $[\lambda F]$ & RR-BLUP $[\lambda \mathrm{L}]$ & Fenótipo & RR-BLUP $[\lambda F]$ & RR-BLUP $[\lambda \mathrm{L}]$ & Fenótipo \\
\hline \multirow{3}{*}{ MA } & RR-BLUP $[\lambda F]$ & - & $98 \%$ & $21 \%$ & $94 \%$ & $93 \%$ & $23 \%$ \\
\hline & RR-BLUP $[\lambda \mathrm{L}]$ & $99 \%$ & - & $22 \%$ & $94 \%$ & $94 \%$ & $23 \%$ \\
\hline & Fenótipo & $64 \%$ & $64 \%$ & - & $23 \%$ & $23 \%$ & $86 \%$ \\
\hline \multirow{3}{*}{ VG } & RR-BLUP $[\lambda F]$ & $98 \%$ & $98 \%$ & $64 \%$ & - & $98 \%$ & $24 \%$ \\
\hline & RR-BLUP $[\lambda L]$ & $98 \%$ & $98 \%$ & $64 \%$ & $99 \%$ & - & $25 \%$ \\
\hline & Fenótipo & $63 \%$ & $63 \%$ & $99 \%$ & $64 \%$ & $64 \%$ & - \\
\hline
\end{tabular}

${ }^{+}$- média ajustada obtida na seleção fenotípica

$\S$ - valor genotípico obtido na seleção fenotípica

Foi também avaliada a coincidência entre 50\% dos indivíduos que teriam sido selecionados com base nos seus valores genotípicos, médias ajustadas e VGGs (de todos os 
cenários de GS) (Tabela 8 - diagonal inferior). As coincidências entre os indivíduos selecionados nos cenários de GS foram de 98 a 99\% para altura de plantas, 98\% para altura de espiga e de 98 a 99\% para produtividade de grãos. A coincidência de indivíduos selecionados pela GS e por seleção fenotípica (média ajustada ou valores genotípicos) foi de $78 \%$ para altura de plantas, 80 a $81 \%$ para altura de espiga e 63 a 64\% para a produtividade de grãos. A coincidência de indivíduos selecionados por médias ajustadas e valores genotípicos foi de 99\% para a altura de planta, 98\% para altura de espiga, e 99\% para a produtividade de grãos.

Para um mesmo tipo de variável dependente, metodologia RR-BLUP[F] foi superior para a altura de espiga em pelo menos um tipo de variável dependente. Para produtividade de grãos e altura de planta não houve diferença. Considerando os diferentes parâmetros de penalização separadamente, observou-se que a coincidência de seleção entre valores genotípicos e VGGs estimados com base em valores genotípicos foi maior do que a correlação das médias ajustadas com os VGGs estimados com médias ajustadas para altura de espiga. Para altura de plantas e produtividade de grãos não houve diferença.

\subsubsection{Discussão}

\subsubsection{Análise fenotípica}

A variabilidade genética é o aspecto mais importante a se considerar em um programa de melhoramento. Neste contexto, foram observadas diferenças genéticas significativas entre os híbridos, logo, suas constituições genotípicas são distintas e potencialmente favoráveis à seleção. Este fato decorre da avaliação de grande número de genótipos (452) obtidos com número razoável de linhagens genitoras (111).

O fator "Local" da análise fenotípica foi considerado como aleatório, e nesta situação assume-se que as estações experimentais formam um conjunto que representa três grandes regiões produtoras de milho no Brasil, o Sul (Paraná), Sudeste (Minas Gerais) e Centro-Oeste (Mato Grosso). Nesta situação, busca-se a seleção de genótipos que possam ser cultivados em toda e qualquer região representada pelo conjunto de localidades avaliadas. Outro enfoque poderia ter sido utilizado para esta avaliação considerando "Local" como efeito de natureza fixa, sendo favorecida a escolha de genótipos para locais específicos, possibilitando explorar ao máximo a interação genótipo $\times$ local, a qual também mostrou-se significativa.

Os coeficientes de variação experimental $\left(C V_{\varepsilon} \%\right)$ apresentaram-se abaixo dos limites máximos considerados para experimentação agrícola (PIMENTEL-GOMES, 2009), representando a confiabilidade das estimativas. As acurácias experimentais foram altas, 
indicando que a condução experimental foi boa o suficiente para seleção confiável dos melhores materiais. A produtividade de grãos é naturalmente mais sujeita aos efeitos ambientais (HALLAUER; CARENA; MIRANDA FILHO, 2010), entretanto, sua avaliação em maior número de locais levou a acurácias semelhantes às demais características.

As características avaliadas são de arquitetura genética complexa (CAI et al., 2012; PEIFFER et al., 2014). As herdabilidades foram maiores para altura de plantas e espigas em comparação a produtividade de grãos, o que é natural pois os componentes de produtividade de grãos como diâmetro e comprimento de espiga são altamente influenciados pelas condições ambientais (HALLAUER; CARENA; MIRANDA FILHO, 2010). Foi observado que a herdabilidade a nível de médias de locais no sentido amplo aumentou em relação à herdabilidade individual, o que pode indicar que apesar de haver efeito significativo da interação genótipo $\times$ local, existe razoável correlação entre o ordenamento das médias dos tratamentos nos diferentes locais.

No melhoramento clássico, faz-se a seleção em experimentos com várias repetições e locais para minimizar o efeito da variação ambiental, aumentando a acurácia experimental. Entretanto, a maior precisão da seleção baseada em médias de locais é alcançada a um custo, geralmente diminuição do tamanho efetivo (LORENZ, 2013), o que implica em intensidade de seleção, diferencial de seleção e ganhos de seleção menores. Nesse contexto, experimentos como dialelos parciais e testcrosses podem ser utilizados para a associação das variações fenotípicas à covariáveis genômicas em uma população de descoberta (SCHRAG et al., 2009). Uma vez associados o fenótipo e suas contrapartes genômicas, pode-se fazer a seleção em uma população com um número extremamente maior de genótipos, ganhos de seleção maiores, sem o uso de repetições ou múltiplos locais de avaliação e com alta eficiência seletiva (RESENDE et al., 2012).

\subsubsection{Controle de qualidade e composição do genótipo dos híbridos}

A composição genômica dos híbridos exigiu a retirada de marcadores que estavam em heterozigose nas linhagens, pois a escolha aleatória de um dos alelos de cada genitor considerando a segregação gênica igual (primeira lei de Mendel) implicaria em erro. As linhagens utilizadas são oriundas de autofecundação, o que explica a grande quantidade de loci ainda em heterozigose. Neste sentido, a associação desta metodologia com a obtenção de linhagens duplo haploides pode resolver este problema, mantendo o número de marcadores em maiores densidades. 
Foi observada grande quantidade de marcadores idênticos (aproximadamente 42,3\%) após o controle de qualidade. Estas situações foram observadas em posições físicas adjacentes, o que demonstra a alta resolução da plataforma, e possivelmente a restrita recombinação de determinadas regiões cromossômicas no conjunto de genótipos avaliados, gerando alto desequilíbrio de ligação entre marcadores. O controle de qualidade e a eliminação de informações redundantes facilitam as análises estatísticas pela diminuição da colinearidade entre as variáveis, redução do tempo e demanda computacional.

\subsubsection{Efeito do parâmetro de penalização nas análises genômicas}

A herdabilidade no sentido restrito a nível de média de locais foi a escolhida para estimação do parâmetro de penalização na metodologia RR-BLUB $[\lambda F]$, pois é a herdabilidade que corresponde ao fenótipo utilizado na GS. As médias ajustadas e valores genotípicos utilizados nas análises foram obtidas sem pedigree, para que apenas o parentesco genômico fosse considerado nas equações (RESENDE et al., 2013).

Houve diferença entre as herdabilidades fenotípicas e moleculares, sendo mais acentuada para a produtividade de grãos, provavelmente devido à natureza quantitativa desta característica. Consequentemente, os parâmetros de penalização associados a predição da produtividade também foram os que mais divergiram. As herdabilidades estimadas com base na variação dos marcadores foram maiores do que as da análise fenotípica para altura de planta e espiga, fato que não se observou para a produtividade.

A avaliação experimental em elevado número de repetições e locais aumenta a acurácia na estimação do componente genético dos híbridos, no entanto, a herdabilidade molecular estimada com base nestes fenótipos mais precisos não necessariamente aumenta na mesma proporção, o que pode ter levado a grande diferença entre a herdabilidades molecular e fenotípica para a produtividade de grãos.

Foi observado na análise de variância que a forma de estimação do parâmetro de penalização não implicou em diferenças significativas na predição da altura de planta e espiga. Apesar de diferirem modestamente, a capacidade preditiva foi maior para a produtividade de grãos quando a estimação do parâmetro foi realizada por REML. Zhao et al. (2013) também observaram que a estimação do parâmetro de penalização por REML resulta em capacidades preditivas maiores. Entretanto, obtiveram melhores resultados quando o parâmetro de penalização foi estimado com base em locais individuais. Assim, pode-se 
afirmar que a estimação iterativa do parâmetro de penalização apresenta melhores resultados, mas deve-se atentar às situações onde a estimação por REML é possivelmente inconsistente.

\subsubsection{Efeito da correção do fenótipo na GS}

$\mathrm{Na}$ avaliação da eficácia da GS optou-se por aferir a capacidade das metodologias em predizer sua própria variável dependente, ou seja, quando as médias ajustadas foram utilizadas para a predição do efeito de substituição das marcas, a correlação (capacidade preditiva) foi estimada entre valores genéticos genômicos preditos e as médias ajustadas observadas dos respectivos indivíduos. O mesmo processo foi realizado para o valor genotípico.

O uso dos valores genotípicos na GS resultou em variâncias genéticas aditivas e residuais menores em comparação a média ajustada, provavelmente devido ao encolhimento sofrido por ele em sua estimação na análise fenotípica, resultando em menor amplitude nos valores das observações. Apesar disso, as herdabilidades moleculares foram semelhantes, indicando a proporcionalidade das metodologias nestas estimações.

O uso de médias ajustadas e valores genotípicos levou a estimação de parâmetros de penalização bastante semelhantes, mas estes foram maiores para as três características quando médias ajustadas foram utilizadas. Apesar do efeito não tão claro na estimação dos parâmetros de penalização, a variável dependente afetou significativamente na capacidade preditiva da GS. As diferenças significativas entre as capacidades preditivas obtidas com médias ajustadas e valores genotípicos foram observadas independentemente da complexidade da característica, sendo que os resultados foram melhores quando o valor genotípico foi utilizado.

Além de proporcionar maior capacidade preditiva, o uso de valor genotípico é apoiado por outros fatores. Por exemplo, a estimação do componente genético com o uso do BLUP na análise fenotípica maximiza a correlação entre os valores genotípicos reais e os valores genotípicos preditos (SEARLE; CASELLA; MCCULLOCH, 2006). Desta forma, parece adequada a utilização deste fenótipo, pois o que queremos predizer são os efeitos passíveis de seleção e/ou transmissão para gerações subsequentes (PIEPHO et al., 2008). Outro fator é a filosofia de uso da população de treinamento, a qual tem de ser uma amostra representativa da população da qual os efeitos dos marcadores são estimados (ISIDRO et al., 2014). Ademais, a tecnologia de duplo-haploides vem sendo cada vez mais utilizada no melhoramento de híbridos. Este tipo de genótipo, ao contrário das linhagens obtidas de forma convencional, 
representam um grupo de combinações genéticas que não necessariamente passaram por processos seletivos (SCHRAG et al., 2009), sendo portanto um conjunto conceitualmente aleatório.

\subsubsection{Efetividade de seleção de genótipos}

Os indivíduos superiores de acordo com os valores genotípicos e médias ajustadas não foram os mesmos. A correção pela herdabilidade individual (no caso do valor genotípico) provavelmente foi o fator que resultou na falta de coincidência completa entre eles, possivelmente devido aos desbalanceamentos estatísticos e genéticos.

Os resultados indicam haver grande semelhança entre os conjuntos de indivíduos que seriam selecionados nos cenários de GS. Entretanto, o que realmente interessa, em termos de melhoramento, é a coincidência de seleção entre a GS e a seleção fenotípica. Para características de maior herdabilidade, como altura de planta e altura de espiga, a coincidência para intensidade moderada foi razoável. Já para a produtividade de grãos, a GS apresentou baixa eficiência. Esta menor coincidência pode ser devido a menor herdabilidade acompanhada da desconsideração da dominância na predição dos efeitos de substituição alélica dos marcadores, visto a importância deste fator na expressão da produtividade de grãos (HALLAUER; CARENA; MIRANDA FILHO, 2010).

Foi observado que a utilização de REML para estimação do parâmetro $\lambda$ rendeu resultados levemente superiores para produtividade de grãos e inferiores para altura de planta e espiga considerando a coincidência com a análise fenotípica sob moderada intensidade de seleção. Sob baixa intensidade de seleção, os métodos de estimação do $\lambda$ resultaram em coincidências semelhantes, exceto para altura de espiga, onde RR-BLUP[F] foi superior. Portanto, não foi observado um padrão resultante do uso do fator "parâmetro de penalização" para seleção dos indivíduos sob moderada e baixa intensidade.

Nas situações em que o tipo de correção do fenótipo afetou a ordenação dos indivíduos, foi observada maior correspondência de ordenamentos entre VGGs e a variável dependente quando o valor genotípico foi utilizado. Pode-se afirmar que existe vantagem no uso valor genotípico como variável dependente da GS, reiterado pelas maiores capacidades preditivas que proporciona e pelos demais fatores apresentados previamente.

A GS demonstrou grande aplicabilidade na seleção sob baixas intensidades. Como mencionado, a GS pode ser aplicada sobre populações de tamanho efetivo grandes, e nestas situações a eliminação de genótipos inferiores é tão importante quanto a seleção sob 
moderadas intensidades. A utilização desta característica em programas de melhoramento pode evitar gastos com a avaliação de genótipos que seriam inevitavelmente descartados em gerações avançadas (SPINDEL et al., 2015, 2016). Dessa forma, pode-se gerar populações sintéticas muito maiores e conduzir para avaliações somente os genótipos mais promissores escolhidos com base em seu padrão genômico.

\subsubsection{Aplicação dos resultados no melhoramento de plantas}

A eficiência da seleção genômica no melhoramento de milho já é comprovada (MASSMAN; JUNG; BERNARDO, 2013). A avaliação por meio da metodologia RR-BLUP apresentou resultados satisfatórios para predição e seleção de híbridos de milho sob baixas intensidades para altura de planta, altura de espiga e produtividade de grãos, indicando seu possível uso para melhoramento destas características.

O grande número de repetições da validação cruzada permitiu que diferenças mínimas entre as capacidades preditivas médias fossem suficientes para discerni-las. De forma geral, a utilização de valores genotípicos como variável dependente e parâmetro de penalização estimado pela variância dos marcadores moleculares parece ser a melhor opção para a predição destas características.

A realização da GS sobre o conjunto de híbridos considerados neste estudo pode ser praticada com diferentes fins. Primeiro, identificar os melhores híbridos para seleção e recombinação de seus genitores dentro de grupos heteróticos em um programa de Seleção Recorrente Genômica Recíproca (SRGR) (FRITSCHE-NETO et al., 2012); segundo, selecionar híbridos mais promissores para ensaios avançados com avaliação em vários locais e; terceiro, eliminar grandes conjuntos de indivíduos menos promissores com base em seu padrão genômico. Dentre estas possibilidades, a terceira mostrou-se altamente promissora como forma de seleção precoce direta, mesmo para a produtividade de grãos, característica de baixa herdabilidade.

\subsection{Conclusões}

- A estimação do parâmetro de penalização (shrinkage factor) com base na herdabilidade no sentido restrito resulta em menor eficiência que sua obtenção por REML visando a predição genômica de híbridos simples de milho tropical.

- O uso de valores genotípicos como variável dependente na seleção genômica conduz a maiores capacidades preditivas em híbridos simples de milho tropical. 
- A GS apresenta maior eficiência sob baixas intensidades de seleção no melhoramento de híbridos de milho tropical.

\section{Referências}

BERNARDO, R.; YU, J. Prospects for Genomewide Selection for Quantitative Traits in Maize. Crop Science, Madison, v. 47, n. 3, p. 1082, 2007.

BROWNING, B.L.; BROWNING, S.R. Unified approach to genotype imputation and haplotype-phase inference for large data sets of trios and unrelated individuals. The American Journal of Human Genetics, Boston, v. 84, n. 2, p. 210-223, 2009.

CAI, H.; CHU, Q.; GU, R.; YUAN, L.; LIU, J.; ZHANG, X.; CHEN, F.; MI, G.; ZHANG, F. Identification of QTLs for plant height, ear height and grain yield in maize (Zea mays L.) in response to nitrogen and phosphorus supply. Plant Breeding, Malden, v. 131, n. 4, p. 502$510,2012$.

ENDELMAN, J.B. Ridge regression and other Kernels for genomic selection with R package rrBLUP. The Plant Genome Journal, Madison, v. 4, n. 3, p. 250-255, 2011.

FRITSCHE-NETO, R. Seleção genômica ampla e novos métodos de melhoramento do milho. 2011. 28 p. Tese (Doutorado em Genética e Melhoramento) - Universidade Federal de Viçosa, Viçosa, 2011.

FRITSCHE-NETO, R.; RESENDE, M.D.V. de; MIRANDA, G.V.; DOVALE, J.C. Seleção genômica ampla e novos métodos de melhoramento do milho. Revista Ceres, Viçosa, v. 59, n. 6, p. 794-802, 2012.

GILMOUR, A.R.; GOGEL, B.J.; CULLIS, B.R.; THOMPSON, R. Asreml user guide release 3.0. Hemel Hempstead: VSN International, 2009. 372 p.

HALLAUER, A.R.; CARENA, M.J.; MIRANDA FILHO, J.B. Quantitative genetics in maize breeding. $3^{\text {rd }}$ ed. New York: Springer-Verlag, 2010. v. 6, 664 p.

HAYES, B.; GODDARD, M. Genome-wide association and genomic selection in animal breeding. Genome, Ottawa, v. 53, n. 11, p. 876-883, 2010.

ISIDRO, J.; JANNINK, J.L.; AKDEMIR, D.; POLAND, J.; HESLOT, N.; SORRELLS, M.E. Training set optimization under population structure in genomic selection. Theoretical and Applied Genetics, Berlin, v.128, n. 1, p. 145-158, 2014.

LORENZ, A.J. Resource allocation for maximizing prediction accuracy and genetic gain of genomic selection in plant breeding: a simulation experiment. G3, Bethesda, v. 3, n. 3, p. 481-491, 2013.

MASSMAN, J.M.; JUNG, H.J.G.; BERNARDO, R. Genomewide selection versus markerassisted recurrent selection to improve grain yield and stover-quality traits for cellulosic 
ethanol in maize. Crop Science, Madison, v. 53, n. 1, p. 58-66, 2013.

MEUWISSEN, T.H.E.; HAYES, B.J.; GODDARD, M.E. Prediction of total genetic value using genome-wide dense marker maps. Genetics, Austin, v. 157, n. 4, p. 1819-1829, 2001.

PEIFFER, J.A.; ROMAY, M.C.; GORE, M.A.; FLINT-GARCIA, S.A.; ZHANG, Z.; MILLARD, M.J.; GARDNER, C.A.C.; MCMULLEN, M.D.; HOLLAND, J.B.; BRADBURY, P.J.; BUCKLER, E.S. The genetic architecture of maize height. Genetics, Austin, v. 196, n. 4, p. 1337-1356, 2014.

PIEPHO, H.P.; MÖHRING, J.; MELCHINGER, A.E.; BÜCHSE, A. BLUP for phenotypic selection in plant breeding and variety testing. Euphytica, Wageningen, v. 161, n. 1/2, p. 209-228, 2008.

PIMENTEL-GOMES, F. Curso de estatística experimental. 15. ed. Piracicaba: FEALQ, 2009. 451p.

R CORE TEAM. R: a language and environment for statistical computing. Vienna: $R$ Foundation for Statistical Computing, 2014.

RESENDE, M.D.V. Matemática e estatística na análise de experimentos e no melhoramento genético. Colombo: Embrapa Florestas, 2007. 561 p.

RESENDE, M.D.V.; DUARTE, J.B. Precisão e controle de qualidade em experimentos de avaliação de cultivares. Pesquisa Agropecuária Tropical, Goiânia, v. 37, n. 3, p. 182-194, 2007.

RESENDE, M.D.V.; SILVA, F.F.; RESENDE, J.R. Seleção genômica ampla. In: BORÉM, A.; FRITSCHE-NETO, R. (Ed.). Biotecnologia aplicada ao melhoramento de plantas. Visconde do Rio Branco: Suprema, 2013. p. 151-188.

RESENDE, M.D.V.; SILVA, F.F.; LOPES, P.S.; AZEVEDO, C.F. Seleção genômica ampla (gws) via modelos mistos (reml/blup), inferência bayesiana $(\mathrm{mcmc})$, regressão aleatória multivariada e estatística espacial. Viçosa: Universidade Federal de Viçosa, Departamento de Estatística, 2012. 291 p.

SCHRAG, T.A.; FRISCH, M.; DHILLON, B.S.; MELCHINGER, A.E. Marker-based prediction of hybrid performance in maize single-crosses involving doubled haploids. Maydica, Bergamo, v. 54, n. 2/3, p. 353-362, 2009.

SEARLE, S.; CASELLA, G.; MCCULLOCH, C. Variance components. Hoboken: John Wiley, 2006. $536 \mathrm{p}$.

SPINDEL, J.; BEGUM, H.; AKDEMIR, D.; VIRK, P.; COLLARD, B.; REDOÑA, E.; ATLIN, G.; JANNINK, J.-L.; MCCOUCH, S.R. Genomic selection and association mapping in rice (Oryza sativa): effect of trait genetic architecture, training population composition, marker number and statistical model on accuracy of rice genomic selection in elite, tropical rice breeding lines. PLoS Genetics, San Francisco, v. 11, n. 2, p. 1-25, 2015.

SPINDEL, J.E.; BEGUM, H.; AKDEMIR, D.; COLLARD, B.; REDOÑA, E.; JANNINK, J.- 
L.; MCCOUCH, S. Genome - wide prediction models that incorporate de novo GWAS are a powerful new tool for tropical rice improvement. Heredity, Edinburgh, v. 116, n. 4, p. 395408, Nov. 2015.

UNTERSEER, S.; BAUER, E.; HABERER, G.; SEIDEL, M.; KNAAK, C.; OUZUNOVA, M.; MEITINGER, T.; STROM, T.M.; FRIES, R.; PAUSCH, H.; BERTANI, C.; DAVASSI, A.; MAYER, K.F.; SCHÖN, C.-C. A powerful tool for genome analysis in maize: development and evaluation of the high density $600 \mathrm{k}$ SNP genotyping array. BMC Genomics, London, v. 15, n. 1, p. 823, Jan. 2014.

WHITTAKER, J.C.; THOMPSON, R.; DENHAM, M. Marker-assisted selection using ridge regression. Genetical Research, Cambridge, v. 75, n. 2, p. 249-255, 2000.

WIMMER, V.; ALBRECHT, T.; AUINGER, H.-J.; SCHON, C.-C. synbreed: a framework for the analysis of genomic prediction data using R. Bioinformatics, Oxford, v. 28, n. 15, p. 2086-2087, 2012.

WÜRSCHUM, T.; REIF, J.C.; KRAFT, T.; JANSSEN, G.; ZHAO, Y. Genomic selection in sugar beet breeding populations. BMC Genetics, London, v. 14, n. 1, p. 85, 2013.

YANG, Z. Molecular evolution: a statistical approach. Oxford: Oxford University Press, 2014. 512 p.

ZHAO, Y.; METTE, M.F.; REIF, J.C. Genomic selection in hybrid breeding. Plant Breeding, Malden, v. 134, n. 1, p. 1-10, 2015.

ZHAO, Y.; METTE, M.F.; GOWDA, M.; LONGIN, C.F.H.; REIF, J.C. Bridging the gap between marker-assisted and genomic selection of heading time and plant height in hybrid wheat. Heredity, Edinburgh, v. 112, n. 6, p. 638-645, 2014.

ZHAO, Y.; GOWDA, M.; LIU, W.; WÜRSCHUM, T.; MAURER, H.P.; LONGIN, F.H.; RANC, N.; PIEPHO, H.P.; REIF, J.C. Choice of shrinkage parameter and prediction of genomic breeding values in elite maize breeding populations. Plant Breeding, Malden, v. 132, n. 1, p. 99-106, 2013. 
PARA CARACTERES OLIGOGÊNICOS VIA MÉTODOS QUE CONSIDERAM SNPS DE MAIOR EFEITO

\section{Resumo}

A capacidade das metodologias de Seleção Genômica (GS) em associar variações genotípicas às fenotípicas está relacionada à arquitetura genética das características. Assim, metodologias que refletem satisfatoriamente a natureza da distribuição dos efeitos dos QTL tendem a ser mais eficazes. Diante deste fato, objetivou-se avaliar a eficiência da modelagem diferencial de marcadores moleculares de maior efeito na capacidade preditiva da metodologia G-BLUP, comparando-a ao LASSO Bayesiano, BayesB e G-BLUP convencional na predição genômica de características oligogênicas de híbridos simples de milho tropical. Para este fim, foram utilizados 452 híbridos simples de milho obtidos por meio do delineamento genético do tipo dialelo parcial a partir de 111 linhagens endogâmicas. Os híbridos foram avaliados no ano de 2015 em experimentos com repetições em cinco locais para produtividade de grãos e três locais para altura de planta e espiga. As linhagens genitoras foram genotipadas com a plataforma Affymetrix ${ }^{\oplus}$ Axiom $^{\bullet}$ Maize Genotyping Array de 616 mil marcadores SNP. A qualidade da informação genômica foi controlada pela eliminação de heterozigotos, Minor Allele Frequency e Call Rate. Por sua vez, a composição genômica dos híbridos foi obtida com a combinação direta do padrão genômico das linhagens genitoras. Os valores genotípicos dos híbridos foram obtidos por meio de equações de modelos mistos do tipo REML/BLUP para posterior uso nas análises genômicas. A análise de GWAS foi utilizada para identificação de marcadores de maior efeito para utilização como fatores fixos na GS via BLUP genômico, aqui denominada GWAS|GS. Essa metodologia foi avaliada em conjunto com o G-BLUP convencional, LASSO Bayesiano e BayesB. As capacidades preditivas foram estimadas por validação cruzada $(k$-fold $)$. As metodologias foram comparadas por meio da análise de variância e teste de Tukey, usando as capacidades preditivas obtidas na validação cruzada como variável resposta. Foram também comparadas quanto a coincidência e ganhos com a seleção, considerando a seleção fenotípica como padrão. Somente altura de planta e espiga apresentaram SNPs de efeito significativo. Foi possível observar que a modelagem específica dos SNPs de efeito significativo aumentou em pequena magnitude a capacidade preditiva do G-BLUP. Além disso, os métodos de maior capacidade preditiva não foram necessariamente os que proporcionam maiores ganhos de seleção, sendo o melhor dependente da intensidade de seleção escolhida. Portanto, a realização do GWAS|GS não se justifica devido à sua subjetividade e maior complexidade. Diante do exposto, o G-BLUP convencional é a metodologia mais indicada para predição das características oligogênicas avaliadas por sua facilidade de condução.

Palavras-chave: Métodos Bayesianos; Arquitetura genética; BLUP genômico; GWAS; Ganho com a seleção

\footnotetext{
Abstract

The ability of the genomic selection (GS) methods in associating genotypic changes to phenotypic variation depends on the genetic architecture of the traits. Therefore, approaches that can accurately reflect the distribution of the QTL effects should be more efficient. Based on this fact, the aim was to asses the efficiency of differential modeling of
} 
major makers on the prediction accuracy of the Genomic BLUP, comparing it to Bayesian LASSO, BayesB and ordinary G-BLUP on the prediction of oligogenic traits of tropical maize single-crosses. To this end, 452 hybrids obtained from partial diallel mating design of 111 inbred lines were utilized. The hybrids were evaluated in 2015 on replicated trials for grain yield at five environments and for plant height and ear height at three. The parental lines were genotyped with 616,201 SNPs using the Affymetrix ${ }^{\circledR}$ Axiom ${ }^{\circ}$ Maize Genotyping Array. The quality control of the genomic information was performed by Minor Allele Frequency and Call Rate procedures and elimination of heterozygous loci. The genomic data of the hybrids was obtained as the combination of the genomic information of their parents. The genotypic values of the hybrids were assessed by REML/BLUP mixed model equations for further use on the genomic analysis. The GWAS was performed to identify major markers to be modeled as fixed effect factors on G-BLUP, a method here referred by GWAS|GS. This method was evaluated along with ordinary G-BLUP, Bayesian LASSO and BayesB. The prediction accuracies were estimated by cross-validation scheme. The methods were compared by Analysis of Variance and Tukey's test using the predictive accuracy obtained from the cross-validation process as response variable. The methods were also evaluated by their selection gain having the phenotypic selection as standard. Only plant and ear height had SNPs with significant effect. The differential modeling of significant SNPs caused little improvement on G-BLUP's prediction accuracy. Furthermore, the methods with higher prediction accuracy were not necessarily the ones that resulted in better selection gains, and the best methodology varied with the changes in the selection intensity. Thus, conducting the GWAS|GS analysis is not worth due to its subjectivity and complexity. Based on these facts, the ordinary G-BLUP should be the method of choice to predict the oligogenic traits evaluated because of its easiness.

Keywords: Bayesian methods; Genetic architecture; Genomic BLUP; GWAS; Selection gain

\subsection{Introdução}

O alcance de altas produtividades em milho (Zea mays L.) é dependente do desenvolvimento de híbridos, o principal produto comercial explorado nesta espécie. Para a identificação dos melhores genótipos é necessária a obtenção e avaliação de centenas a milhares de combinações, o que demanda muito tempo e recursos (SCHRAG et al., 2009). Para contornar este problema, existem diversas metodologias de predição de indivíduos não avaliados, as quais utilizam apenas dados fenotípicos ou da combinação destes com informações genômicas (SCHRAG et al., 2009; ZHAO; METTE; REIF, 2015). Neste contexto, a predição genômica tornar-se-á cada vez mais vantajosa em relação à avaliação a campo em decorrência do avanço tecnológico (BERNARDO, 2008). Portanto, é necessário o constante aprimoramento de metodologias que façam uso destas informações e proporcionem predições acuradas de forma economicamente viável.

A Seleção Auxiliada por Marcadores (MAS) (LANDE; THOMPSON, 1990) é uma técnica bastante difundida no melhoramento genético de plantas. Entretanto, sabe-se que existe grande diferença entre a variância genética explicada por marcas significativas e a 
variância genética total (BERNARDO, 2014; HAYES; GODDARD, 2010). Para capturar esta variância, foi proposta a Seleção Genômica (GS) (MEUWISSEN; HAYES; GODDARD, 2001). Esta é uma técnica que dispensa testes de significância na identificação de associação entre marcas e QTL, usando-se da soma de pequenas variâncias oriundas de um grande número de marcas para explicar a máxima variação possível.

A capacidade dos métodos de GS em associar mudanças genotípicas às variações fenotípicas esta relacionada à arquitetura genética das características (BERNARDO, 2008; MEUWISSEN; HAYES; GODDARD, 2001; RESENDE et al., 2012b). Tem-se observado que, quão maior seja a semelhança entre a distribuição assumida a priori e a distribuição real dos efeitos dos QTL, maior é a acurácia dos valores genéticos preditos (HAYES; GODDARD, 2010). Neste contexto, é comum que a distribuição real dos efeitos genéticos que controlam uma determinada características assumam várias formas, em que a presença de genes de maior efeito pode levar a predições menos acuradas de algumas metodologias (RESENDE; SILVA; RESENDE JÚNIOR, 2013).

Metodologias Bayesianas têm a capacidade de considerar variâncias locus-específicas e, de forma geral, têm sido consideradas mais eficientes que métodos baseados em modelos mistos na predição de características oligogênicas. O LASSO (Least Absolute Shrinkage and Selection Operator) Bayesiano (PARK; CASELLA, 2008) e o BayesB (MEUWISSEN; HAYES; GODDARD, 2001), por exemplo, são metodologias amplamente utilizadas, as quais conseguem refletir satisfatoriamente a natureza da distribuição dos efeitos dos QTL das características que não seguem a normalidade (LEGARRA et al., 2011; RESENDE et al., 2013).

Uma das formas de investigação da arquitetura genética e identificação de marcadores de maior efeito é a Genômica de Associação (GWAS). Esta tem sido extensivamente utilizada na descoberta da base genética de características agronomicamente importantes do milho (Zea mays L.), como arquitetura foliar (TIAN et al., 2011), concentração e composição do óleo da semente (LI et al., 2013), resistência a doenças (GOWDA et al., 2015; MAMMADOV et al., 2015), desenvolvimento radicular (PACE et al., 2015), altura de planta (PEIFFER et al., 2014), entre muitas outras. Estas pesquisas demonstram que essa técnica é eficiente na descoberta de genes candidatos com efeito significativo sobre o fenótipo, os quais podem ser utilizados no processo de melhoramento. Assim, existe a possibilidade de integração direta entre GS e GWAS (SPINDEL et al., 2016), visando melhorar a seleção baseada em marcadores. 
Considerando que os métodos de GS baseados em equações de modelos mistos atuais não tratam diferentemente QTL de maior e de menor efeito (BERNARDO, 2014), tem-se buscado formas para incorporar estas informações na GS, acomodando QTL mais importantes de forma diferenciada (BERNARDO, 2014; HENGDE; WANG; BAO, 2015; ZHAO et al., 2014). Essa modelagem específica de genes conhecidos e poligenes tem sido favorável em algumas situações, proporcionando predições mais acuradas (BERNARDO, 2014; HENGDE; WANG; BAO, 2015; SPINDEL et al., 2016; ZHAO et al., 2014). Diante do exposto, objetivou-se avaliar a eficiência da modelagem diferencial de SNPs de efeito significativo na capacidade preditiva da metodologia G-BLUP (VANRADEN, 2008), compondo uma metodologia aqui denominada GWAS|GS e comparando-a ao LASSO Bayesiano, BayesB e G-BLUP convencional nas predições em uma população real de híbridos simples de milho.

\subsection{Desenvolvimento}

\subsubsection{Objetivos}

\subsubsection{Objetivo geral}

Verificar se a modelagem diferencial de SNPs associados a QTL de maior efeito melhora a capacidade preditiva e seletiva de modelos de seleção genômica baseados em modelos mistos para características oligogênicas em híbridos simples de milho tropical.

\subsubsection{Objetivos específicos}

- Verificar se a modelagem específica de SNPs de efeito significativo identificados por meio de GWAS melhora a capacidade preditiva do G-BLUP (GWAS|GS).

- Avaliar se os métodos de seleção genômica G-BLUP, GWAS|GS, BayesB e LASSO Bayesiano são adequados para a predição e seleção de características oligogênicas em híbridos de milho tropical.

\subsubsection{Material e Métodos}

\subsubsection{População de treinamento e dados fenotípicos}

Foi realizada a avaliação fenotípica de 452 híbridos de milho tropical destinados ao cultivo no Brasil. Estes foram obtidos pelo delineamento genético do tipo dialelo parcial, a partir de 111 linhagens genitoras. As parcelas foram compostas por duas linhas de cinco metros, espaçadas $0,7 \mathrm{~m}$. As características agromorfológicas avaliadas foram altura de planta 
$(\mathrm{cm})$, altura de espiga $(\mathrm{cm})$, e produtividade de grãos $\left(\mathrm{kg} \mathrm{ha}^{-1}\right)$. A altura de planta e espiga foram avaliadas com base em uma planta representativa da parcela, em que a primeira foi medida do solo até a folha bandeira, e a segunda do solo até a base da espiga. As mensurações de altura foram realizadas no quinto estádio reprodutivo (R5). A produtividade de grãos foi obtida com a colheita mecanizada de toda a parcela. Os experimentos foram conduzidos em Ipiaçú-MG, Patos de Minas-MG, Sertanópolis-PR, Nova Mutum-MT e Sorriso-MT no ano agrícola de 2015. Os ensaios foram delineados em blocos casualizados com duas repetições. Altura de plantas e de espigas foram avaliadas somente nos três primeiros locais mencionados. A produtividade de grãos foi ajustada considerando padronização da umidade para $13 \%$. Foi avaliado o efeito genético sobre o estabelecimento do estande com ajuste da produtividade quando na sua ausência. A empresa Helix Sementes Ltda. foi responsável pela condução experimental dos híbridos e obtenção dos dados genotípicos das linhagens genitoras.

\subsubsection{Dados genômicos}

Foram obtidas amostras de DNA das 111 linhagens utilizadas na obtenção dos híbridos, as quais foram genotipadas com a plataforma Affymetrix ${ }^{\bullet}$ Axiom $^{\circledR}$ Maize Genotyping Array de 616.201 (616k) marcadores moleculares de polimorfismo de base única (SNP) (UNTERSEER et al., 2014). A qualidade da informação genômica foi controlada pelos procedimentos de Call Rate (CR) e Minor Allele Frequency (MAF). Marcadores e indivíduos (linhagens) com mais de $5 \%$ de valores perdidos $(\mathrm{CR}<0,95)$ foram eliminados. Os dados genômicos perdidos restantes (nas linhagens) foram imputados com o software Beagle 4.0 (BROWNING; BROWNING, 2009) por meio do pacote Synbreed (WIMMER et al., 2012). O padrão genômico dos híbridos foi obtido por meio da combinação alélica de marcadores homozigotos das linhagens genitoras. Marcadores do conjunto de híbridos com MAF $<0,05$ foram também eliminados, bem como os marcadores idênticos.

\subsubsection{Análise de Deviance e predição dos valores genotípicos}

Os fenótipos dos híbridos foram avaliados por meio de equações de modelos mistos. Fatores de efeito fixo foram testados pelo teste de Wald (GILMOUR et al., 2009) e os aleatórios pelo teste da razão de verossimilhança (Likelihood Ratio Test - LRT) por meio da Análise de Deviance (ANADEV), como descrito em Fritsche-Neto (2011). 
A estimação dos componentes de variância e a predição dos valores genotípicos foram realizados por meio do método da Máxima Verossimilhança Restrita/Melhor Preditor Linear Não Viesado (REML/BLUP) (RESENDE, 2007), considerando o modelo:

$$
\boldsymbol{y}=X \boldsymbol{r}+H \boldsymbol{g}+P \boldsymbol{a}+C \boldsymbol{i}+\boldsymbol{\varepsilon}
$$

em que $\boldsymbol{y}$ : é o vetor de observações fenotípicas dos híbridos; $\boldsymbol{r}$ : é o efeito de bloco, considerado como fixo e somado à média geral; $\boldsymbol{u}$ : vetor dos efeitos genotípicos, considerados como aleatórios, em que $\boldsymbol{g} \sim N I D\left(0, I \sigma_{g}^{2}\right) ; \boldsymbol{a}$ : vetor dos efeitos aleatórios de local, onde $\boldsymbol{a} \sim N I D\left(0, I \sigma_{a}^{2}\right) ; \boldsymbol{i}$ : vetor de efeitos da interação genótipo $\times$ local, considerados aleatórios, em que $\boldsymbol{i} \sim N I D\left(0, I \sigma_{g \times a}^{2}\right)$; $\boldsymbol{\varepsilon}$ : é o vetor de erros, onde $\boldsymbol{\varepsilon} \sim N I D\left(0, I \sigma_{\varepsilon}^{2}\right) . X, H, P$, e $C$ são matrizes de incidência relacionadas aos os efeitos mencionados. O pacote ASReml-R (GILMOUR et al., 2009) do software R (R CORE TEAM, 2014) foi utilizado para estas análises.

A herdabilidade foi estimada a nível de indivíduo por $h_{g i}^{2}=\frac{\sigma_{g}^{2}}{\left(\sigma_{g}^{2}+\sigma_{g \times a}^{2}+\sigma_{\varepsilon}^{2}\right)}$ e médias de locais por $h_{g m}^{2}=\frac{\sigma_{g}^{2}}{\left(\sigma_{g}^{2}+\frac{\sigma_{g \times a}^{2}}{l}+\frac{\sigma_{\varepsilon}^{2}}{r l}\right)}$; em que $\sigma_{g}^{2}$ é a variância genotípica, $\sigma_{g \times a}^{2}$ é a variância da interação genótipo $\times$ local, $\sigma_{\varepsilon}^{2}$ é a variância residual, $r$ é o número de repetições e $l$ é o número de locais.

A acurácia experimental foi estimada pela equação $\hat{r}_{g g}=\left[1-\frac{1}{1+r l . C V_{R}^{2}}\right]^{1 / 2}$; em que $C V_{R}$ é o coeficiente de variação relativa dado por $C V_{R}=\frac{C V_{g}}{C V_{\varepsilon}}$, onde $C V_{g}$ é o coeficiente de variação genotípica $\left(C V_{g}=\left(\sqrt{\sigma_{g}^{2}} / \mu\right) \times 100\right)$ e $C V_{\varepsilon}$ é o coeficiente de variação experimental $\left(C V_{\varepsilon}=\left(\sqrt{\sigma_{\varepsilon}^{2}} / \mu\right) \times 100\right) ; \mu$ é a média geral, $\sigma_{g}^{2}$ é a variância genotípica e $\sigma_{\varepsilon}^{2}$ é a variância residual (RESENDE; DUARTE, 2007).

\subsubsection{Seleção de marcadores}

A GWAS foi realizada considerando o seguinte modelo de regressão em marcas simples visando à associação entre marcadores e regiões genômicas de efeito sobre a características (LIPKA et al., 2012):

$$
\boldsymbol{y}=X \boldsymbol{m}+T \boldsymbol{v}+\boldsymbol{\varepsilon}
$$


em que $\boldsymbol{y}$ é o vetor de valores genotípicos dos híbridos para os caracteres avaliados; $\boldsymbol{m}$ é o vetor de efeitos fixos incluindo o dos marcadores genéticos, estrutura de população e média; $\boldsymbol{v}$ é vetor de efeitos genéticos aditivos de múltiplos QTL com $\boldsymbol{v} \sim N\left(0, G \sigma_{a}^{2}\right)$, onde $G$ é a matriz de parentesco genético aditivo obtida por $G=Z Z^{\prime} / \sum_{i=1}^{n}\left(2 p_{i} q_{i}\right)$, em que $Z$ é a matriz de marcadores, $p_{i}$ e $q_{i}$ são as frequências alélicas; $X$ e $T$ são as matrizes de incidência para os vetores $\boldsymbol{m}$ e $\boldsymbol{v} ; \boldsymbol{\varepsilon}$ refere-se ao vetor de resíduos aleatórios onde $\boldsymbol{\varepsilon} \sim N I D\left(0, I \sigma_{\varepsilon}^{2}\right)$. Nos testes de significância dos $p$-valores, foi utilizado o método FDR (False Discovery Rate), representado por $F D R=m a P m a ́ x / n$, em que Pmáx é o maior $p$-valor de QTL que excede o nível de significância, $n$ é o número de QTL que excedem o nível de significância e $m a$ é o número de marcadores testados (WELLER et al., 1998). Esta análise foi realizada com o pacote GAPIT (LIPKA et al., 2012) do software R.

Os marcadores identificados como significativos pela GWAS foram separados dos demais, sendo criadas duas matrizes de incidência de marcadores, a $M$ de marcas de efeito significativo e a $W$ de poligenes.

\subsubsection{Métodos de GS}

A seleção genômica foi aplicada sobre as características que apresentaram marcadores moleculares de efeito significativo pela análise de GWAS. A combinação de G-BLUP e GWAS, referida por GWAS|GS, representa a modelagem de SNPs significativos como componente fixo nas equações do G-BLUP, como apresentado adiante. Desse modo, foi avaliada a capacidade preditiva de quatro métodos de seleção genômica, nominalmente, GBLUP, GWAS|GS, BayesB e LASSO Bayesiano.

Para condução do G-BLUP foram feitas adaptações à metodologia para acomodação das duas matrizes de marcadores, $W$ e $M$, obtidas a partir dos resultados da GWAS. Os marcadores de $M$ foram consideradas fatores fixos (GWAS|GS), sendo:

$$
\begin{array}{lll}
\boldsymbol{y}=X u+T \boldsymbol{o}+\boldsymbol{e}: & {\left[\begin{array}{ccc}
X^{\prime} X & X^{\prime} T \\
T^{\prime} X & T^{\prime} T+G_{Z}^{-} \lambda_{t}
\end{array}\right]\left[\begin{array}{l}
\hat{\mu} \\
\widehat{\boldsymbol{o}}
\end{array}\right]=\left[\begin{array}{c}
X^{\prime} \boldsymbol{y} \\
T^{\prime} \boldsymbol{y}
\end{array}\right] \quad \text { G-BLUP convencional; e }} \\
\boldsymbol{y}=X u+M \boldsymbol{f}+T \boldsymbol{g}+\boldsymbol{e}: & {\left[\begin{array}{ccc}
X^{\prime} X & X^{\prime} M & X^{\prime} T \\
M^{\prime} X & M^{\prime} M & M^{\prime} T \\
T^{\prime} X & T^{\prime} M & T^{\prime} T+G_{W}^{-} \lambda_{g}
\end{array}\right]\left[\begin{array}{l}
\hat{\mu} \\
\hat{\boldsymbol{f}} \\
\widehat{\boldsymbol{g}}
\end{array}\right]=\left[\begin{array}{c}
X^{\prime} \boldsymbol{y} \\
M^{\prime} \boldsymbol{y} \\
T^{\prime} \boldsymbol{y}
\end{array}\right] \quad \text { GWAS } \mid \mathrm{GS}}
\end{array}
$$

com: $\lambda_{t}=\sigma_{e t}^{2} / \sigma_{a t}^{2}$ e $\lambda_{g}=\sigma_{e g}^{2} / \sigma_{a g}^{2}$ 
onde: $\hat{\mu}$ é a média; $\widehat{o}$ é o vetor de valores genéticos associados à matriz $T$ com $\widehat{\boldsymbol{o}} \sim N I D\left(0, G_{Z}\right) ; G_{Z}$ é a matriz de parentesco aditiva baseada nos marcadores de $Z$ (sem GWAS). Para o método modificado de G-BLUP, $\widehat{\boldsymbol{f}}$ é o valor genético relacionado aos marcadores significativos; $\widehat{\boldsymbol{g}}$ é o vetor de valores genéticos associados aos marcadores não significativos, onde $\widehat{\boldsymbol{g}} \sim \operatorname{NID}\left(0, G_{W}\right) ; X$ é a matriz de incidência para a média, $M$ é a matriz de incidência de marcadores significativos e $T$ é a matriz que associa $\widehat{\boldsymbol{g}}$ a $\boldsymbol{y} ; G_{W}$ é a matriz de parentesco aditiva baseada nos marcadores não significativos;

A predição do efeito das marcas com o BayesB foi realizada como proposto por Meuwissen, Hayes e Goddard (2001), seguindo o seguinte modelo:

$$
\boldsymbol{y}=\boldsymbol{j} \mu+Z \boldsymbol{\beta}+\boldsymbol{e}
$$

onde: $\boldsymbol{y}$ é o vetor de valores genotípicos dos híbridos; $\mu$ é a média geral associada a $\boldsymbol{j}$ (vetor de números um); $Z$ é a matriz de incidência genômica associada a $\boldsymbol{\beta}$, o qual é o vetor de efeitos dos SNPs com mistura de distribuições das marcas assumidas a priori como:

$$
\boldsymbol{\beta}=\left\{\begin{array}{lr}
0 & \text { com probabilidade } \pi \\
N\left(0, \sigma_{\beta_{i}}^{2}\right) & \text { com probabilidade }(1-\pi)
\end{array}\right.
$$

e variância dos marcadores com alta densidade em $\sigma_{\beta}^{2}=0$ e qui-quadrado invertida para $\sigma_{\beta}^{2}>0$, ou seja:

$$
\begin{array}{lr}
\sigma_{\beta_{i}}^{2}=0 & \text { com probabilidade } \pi \\
\sigma_{\beta_{i}}^{2} \sim \chi^{-2}\left(\nu, S^{2}\right) & \text { com probabilidade }(1-\pi)
\end{array}
$$

onde: $v$ é o número de graus de liberdade, $S$ é parâmetro de escala e $\pi$ o parâmetro com distribuição Beta que indica a proporção de marcadores com variância nula; $\boldsymbol{e}$ é o vetor dos efeitos residuais. Os hiperparâmetros foram aplicados como apresentado em Pérez e De Los Campos (2014).

A predição do efeito das marcas pelo método LASSO Bayesiano foi realizada como proposto por Park e Cassela (2008), considerando a priori distribuição exponencial dos efeitos das marcas. As pressuposições desta metodologia implicam em grande proporção dos SNPs com efeito próximo a zero e uma pequena proporção com efeito moderado a grande. 
O modelo para predição do efeito dos marcadores tem a forma:

$$
\boldsymbol{y}=\boldsymbol{j} \mu+Z \boldsymbol{\alpha}+\boldsymbol{e}
$$

onde: $\boldsymbol{y}$ é o vetor de valores genotípicos; $\mu$ é a média geral associada ao vetor coluna $\boldsymbol{j} ; Z$ é a matriz de incidência de $\boldsymbol{\alpha}$, o qual é o vetor de efeitos aditivos dos SNPs dado por:

$$
\left.p\left(\boldsymbol{\alpha} \mid \sigma^{2}, \lambda\right)=\left(\frac{\lambda}{2 \sigma}\right) \exp [-\lambda|\boldsymbol{\alpha}|) / \sigma\right]
$$

considerando um componente de variância $\tau_{i}^{2}$ associado a cada marcador tem-se:

$$
\begin{gathered}
p(\boldsymbol{\alpha} \mid \boldsymbol{\tau}) \sim N\left(0, D \sigma^{2}\right) \quad \text { onde } \operatorname{diag}(D)=\left(\tau_{1}^{2} \ldots \tau_{n}^{2}\right) \\
p(\boldsymbol{\tau} \mid \lambda)=\prod_{i}\left(\frac{\lambda^{2}}{2}\right) \exp \left(-\lambda^{2} \tau_{i}^{2} / 2\right)
\end{gathered}
$$

onde o parâmetro de forma da distribuição dos efeitos dos marcadores é dado por $\lambda^{2}=$ $2 \sigma_{e}^{2} / \sigma_{\alpha}^{2}$

Assim $\operatorname{Var}(\boldsymbol{\alpha})=\left(2 \sigma_{e}^{2}\right) / \lambda^{2}$ e $\operatorname{Var}\left(\alpha_{i}\right)=\sigma_{\alpha_{i}}^{2}=\tau_{i}^{2} \sigma^{2} ; \boldsymbol{e}$ é o vetor de erros onde $e \mid \sigma^{2} \sim M V N\left(0, I \sigma^{2}\right)$.

Foram utilizadas 25.000 iterações com eliminação das 1.000 primeiras e thinning de 5 para realização do BayesB e LASSO Bayesiano. A implementação do LASSO Bayesiano e BayesB foi realizada com o auxílio do pacote BGLR (PÉREZ; DE LOS CAMPOS, 2014) e o G-BLUP com o pacote rrBLUP (ENDELMAN, 2011), ambos do software R.

Os valores genéticos genômicos (VGG) dos híbridos foram obtidos por $\boldsymbol{V} \boldsymbol{G} \boldsymbol{G}=\boldsymbol{M} \widehat{\boldsymbol{f}}+$ $T \widehat{\boldsymbol{g}}$ para $\mathrm{GWAS} \mid \mathrm{GS}$, e $\boldsymbol{V} \boldsymbol{G} \boldsymbol{G}=T \widehat{\boldsymbol{o}}$ para o G-BLUP, $\boldsymbol{V} \boldsymbol{G} \boldsymbol{G}=Z \widehat{\boldsymbol{\beta}}$ para BayesB e $\boldsymbol{V} \boldsymbol{G} \boldsymbol{G}=Z \widehat{\boldsymbol{\alpha}}$ LASSO Bayesiano.

\subsubsection{Obtenção das capacidades preditivas por validação cruzada}

A avaliação da eficiência dos cenários estudados foi realizada com base em validação cruzada de grupos $(k-f o l d)$. As capacidades preditivas $\left(r_{y g}\right)$ foram obtidas da seguinte forma:

1. Distribuição aleatória dos indivíduos em 5 grupos $(\mathrm{N}=5)$;

2. Omissão dos valores genotípicos (variável dependente) do grupo $N_{i}$;

3. Predição dos VGG dos indivíduos de cada grupo $\left(N_{i}\right)$ com base no efeito das 
marcas/parentesco dos grupos restantes e obtenção da correlação de Pearson entre VGG e os valores genotípicos;

4. Repetir os passos 1:3 por 20 vezes utilizando grupos comuns entre todos cenários;

5. Estimar a média das 20 repetições, a qual representa a capacidade preditiva média $\left(r_{y g}\right)$ do modelo.

As metodologias foram comparadas por meio da análise de variância (ANAVA) das capacidades preditivas obtidas nas validações cruzadas. As variáveis explicativas da capacidade preditiva (variável dependente) foram os modelos de GS. O teste F foi utilizado para verificar diferenças estatisticamente significativas entre métodos de seleção genômica para as características avaliadas. Em seguida o teste de Tukey foi utilizado para comparação das capacidades preditivas.

\subsubsection{Ganhos e coincidência de seleção}

Foi avaliada a coincidência de seleção com base nos 11 indivíduos (10\%) com os melhores valores genéticos (genômicos) escolhidos em cada metodologia. Foi então analisada a correlação de ordenamentos com base no coeficiente de correlação de postos de Spearman sobre o conjunto total de indivíduos.

Considerando a mesma intensidade de seleção, foram estimados os ganhos com seleção. Para isso foram utilizados os valores genotípicos (estimados pela análise fenotípica) dos híbridos para a obtenção do ganho de seleção (GSel$\%$ ) que teria sido obtido em cada metodologia de seleção genômica por meio da equação:

$$
G S e l_{\%}=\left[\frac{\left(\sum_{h}^{n} V G_{h} / n\right)}{\bar{x}}\right] \times 100
$$

sendo $V G_{h}$ os valores genotípicos do híbrido $h, n$ o número de híbridos selecionados (11) e $\bar{x}$ a média da variável considerada.

Foi também estimada a eficiência das metodologias de GS em relação à fenotípica considerando como o cenário padrão de melhoramento a Seleção Recorrente:

$$
E R_{G S \%}=\frac{G S e l_{\%} \cdot T_{F e n}}{G S e l_{F e n} \cdot T_{G S}} \times 100
$$


em que $G S e l_{\%}$ é o ganho de seleção estimado na equação anterior (para seleção genômica e fenotípica) e $T$ é o tempo (em anos) do ciclo de cada método de melhoramento, sendo 1,5 para Seleção Recorrente Fenotípica $\left(T_{F e n}\right)$ e 0,5 para a Seleção Recorrente Genômica $\left(T_{G S}\right)$ (FRITSCHE-NETO et al., 2012). A coincidência e os ganhos de seleção foram estimados considerando o procedimento de validação independente, com divisão dos indivíduos em cinco grupos.

\subsubsection{Resultados}

\subsubsection{Análise de Deviance e estimativa dos parâmetros genéticos}

Os componentes de variância residuais dos experimentos realizados nas cinco localidades apresentaram-se relativamente homogêneos sendo apresentada apenas a análise conjunta destes. Não houve diferença significativa entre repetições. A análise de Deviance indicou haver diferenças genéticas significativas no conjunto de híbridos para cada uma das características, bem como diferenças entre os locais de avaliação e interação significativa genótipo $\times$ local (Tabela 9).

Tabela 9 - Teste de Wald para efeitos fixos e teste da razão de verossimilhança (LRT) para efeitos aleatórios estimados via REML/BLUP para altura de planta, altura de espiga e produtividade de grãos em híbridos de milho tropical

\begin{tabular}{|c|c|c|c|}
\hline Fonte de variação & \multirow{2}{*}{ Altura de planta ${ }^{1}$} & \multirow{2}{*}{ Altura de espiga ${ }^{1}$} & \multirow{2}{*}{ Produtividade $^{2}$} \\
\hline Fixo $^{\mathrm{F}}$ & & & \\
\hline Repetição & $1,90^{\mathrm{NS}}$ & $1,30^{\mathrm{NS}}$ & $0,01^{\mathrm{NS}}$ \\
\hline \multicolumn{4}{|l|}{ Aleatório $^{\mathrm{R}}$} \\
\hline Local & $354,91 * * *$ & $362,50 * * *$ & $1229,47 * * *$ \\
\hline Genótipo & $541,79 * * *$ & $492,26 * * *$ & $306,09 * * *$ \\
\hline Genótipo $\times$ Local & $117,48^{* * *}$ & $108,29 * * *$ & $406,96 * * *$ \\
\hline
\end{tabular}

Significativo a $* * * P=0,001$ por LRT ou $\mathrm{F}$ de Wald; ${ }^{\mathrm{NS}}$ - não significativo;

${ }^{1}$ - avaliado em três locais; ${ }^{2}$ - avaliado em cinco locais;

$\mathrm{F}$ - valores avaliados pelo $\mathrm{F}$ de Wald;

${ }^{\mathrm{R}}$ - valores avaliados pelo teste $\chi^{2}$ com um grau de liberdade

As herdabilidades no sentido amplo a nível de médias de locais foram 0,89, 0,87 e 0,78 para altura de plantas, altura de espigas e produtividade de grãos, respectivamente. A produtividade foi a característica que apresentou menor herdabilidade individual no sentido amplo (0,34). Para altura de espiga e altura de planta elas foram de 0,58 e 0,63, respectivamente. Apesar da menor herdabilidade, a produtividade de grãos foi a característica que apresentou maior coeficiente de variação genotípica, seguido da altura de espiga e altura de plantas. Os coeficientes de variação experimental foram médios a baixos, sendo o maior 
deles 12,42 correspondente à produtividade (PIMENTEL-GOMES, 2009). As acurácias seletivas $\left(\hat{r}_{g g}\right)$ foram altas para altura de planta $(0,97)$, altura de espiga $(0,95)$ e produtividade de grãos $(0,95)$, segundo a escala proposta por Resende e Duarte (2007).

Tabela 10 - Valores da herdabilidade sentido amplo a nível de indivíduos $\left(h_{g i}^{2}\right)$ e médias de locais $\left(h_{g m}^{2}\right)$, média $(\bar{x})$, coeficientes de variação genético $\left(C V_{g} \%\right)$ e residual $\left(C V_{\varepsilon} \%\right)$, acurácia a nível de médias de locais $\left(\hat{r}_{g g}\right)$ para altura de planta, altura de espiga e produtividade de grãos avaliados em híbridos milho tropical

\begin{tabular}{lccc}
\hline Parâmetro & Altura de planta $(\mathrm{cm})^{\mathrm{T}}$ & Altura de espiga $(\mathrm{cm})^{\mathrm{T}}$ & Produtividade $\left(\mathrm{kg} \mathrm{ha}^{-1}\right)^{\mathrm{C}}$ \\
\hline$h_{g m}^{2}$ & 0,89 & 0,87 & 0,78 \\
$h_{g i}^{2}$ & 0,63 & 0,58 & 0,34 \\
$\bar{x}$ & 241,25 & 129,55 & 7380,15 \\
\hline$C V_{g} \%$ & 6,04 & 8,30 & 12,51 \\
$C V_{\varepsilon} \%$ & 3,84 & 6,19 & 12,42 \\
\hline$\hat{r}_{g g}$ & 0,97 & 0,95 & 0,95 \\
\hline${ }^{\mathrm{T}}-$ avaliado em três locais; ${ }^{\mathrm{C}}{ }^{-}$-avaliado em cinco locais &
\end{tabular}

\subsubsection{Análise de associação genômica (GWAS)}

O controle de qualidade realizado pela eliminação de marcadores heterozigóticos acompanhada dos procedimentos de MAF e CR reduziu o número de marcadores de 616.201 para 30.471, os quais foram utilizados nas análises genômicas. Foram encontradas 13 associações significativas entre QTL e marcadores moleculares para a altura de planta (Tabela 11) e sete para a altura de espiga (Tabela 12).

Tabela 11 - Resultado da análise de GWAS para altura de planta em híbridos de milho tropical com frequência do alelo secundário (MAF), $p$-valor ajustado $\left(p_{\text {aj }}\right)$ e porcentagem da variação fenotípica explicada (\%Var) de cada marcador molecular

\begin{tabular}{lcccc}
\hline SNP & Cromossomo & MAF & $p_{\text {aj }}$ & $\%$ Var \\
\hline SNP1 & 7 & 0,10 & 0,00003 & 0,0416 \\
SNP2 & 3 & 0,16 & 0,00003 & 0,0405 \\
SNP3 & 7 & 0,09 & 0,00006 & 0,0384 \\
SNP4 & 3 & 0,09 & 0,00036 & 0,0333 \\
SNP5 & 3 & 0,05 & 0,00036 & 0,0331 \\
SNP6 & 10 & 0,47 & 0,00052 & 0,0318 \\
SNP7 & 1 & 0,16 & 0,00052 & 0,0314 \\
SNP8 & 3 & 0,07 & 0,00052 & 0,0312 \\
SNP9 & 3 & 0,10 & 0,00062 & 0,0306 \\
SNP10 & 5 & 0,18 & 0,00063 & 0,0303 \\
SNP11 & 0,18 & 0,00063 & 0,0301 \\
SNP12 & 3 & 0,14 & 0,00068 & 0,0297 \\
SNP13 & 3 & 0,09 & 0,00070 & 0,0295 \\
\hline Total & 3 & & & 0,4315 \\
\hline
\end{tabular}


Tabela 12 - Resultado da análise de GWAS para altura de espiga em híbridos de milho tropical frequência do alelo secundário (MAF), $p$-valor ajustado $\left(p_{\text {aj }}\right)$ e porcentagem da variação fenotípica explicada (\%Var) de cada marcador molecular

\begin{tabular}{lcccc}
\hline SNP & Cromossomo & MAF & $p_{\text {aj }}$ & $\%$ Var \\
\hline SNP1 & 7 & 0,10 & 0,0013 & 0,0316 \\
SNP4 & 3 & 0,09 & 0,0013 & 0,0310 \\
SNP2 & 3 & 0,16 & 0,0013 & 0,0305 \\
SNP6 & 10 & 0,47 & 0,0013 & 0,0302 \\
SNP11 & 3 & 0,18 & 0,0013 & 0,0302 \\
SNP14 & 2 & 0,07 & 0,0013 & 0,0300 \\
SNP8 & 3 & 0,07 & 0,0013 & 0,0298 \\
\hline Total & & & 0,2133 \\
\hline
\end{tabular}

Os SNPs 1, 2, 4, 6, 8 e 11 estão associados a QTL que controlam ambas as características, o que indica elevada correlação genética. Apenas o SNP 14 associado ao controle da altura de espiga não foi identificado como significativo para altura de planta. Nenhuma associação foi encontrada entre os marcadores utilizados e QTL controlando a produtividade de grãos. Com isto, para as análises seguintes foram consideradas apenas a altura de planta e altura de espiga.

A maioria dos QTL foram encontrados no cromossomo 3 para ambas as características. De forma geral, os marcadores associados a QTL apresentaram baixa frequência do alelo secundário, sendo que apenas o SNP 6 apresentou MAF>0,2. O QTL responsável pela maior variação no valor genotípico foi o mesmo para as alturas de planta e espiga (SNP 1), representando respectivamente 0,0416 e $0,0316 \%$ da variação fenotípica total.

\subsubsection{Capacidade preditiva das metodologias}

A divergência entre as capacidades preditivas dos modelos testados foi avaliada por meio da análise de variância das médias das reamostragens das validações cruzadas. Houve diferença significativa entre a capacidade preditiva dos métodos de seleção genômica para altura de plantas e altura de espigas por meio do teste F (Tabela 13).

Tabela 13 - Resumo da análise de variância para os efeitos de métodos de seleção genômica (G-BLUP, GWAS|GS, LASSO Bayesiano e BayesB) considerando altura de plantas e altura de espiga em híbridos de milho tropical

\begin{tabular}{lcc}
\hline \multicolumn{1}{c}{ Fonte de variação } & Altura de planta & Altura de espiga \\
\hline Método de GS & $5,14^{* *}$ & $4,06^{* *}$ \\
\hline Significativo a $0,01(* *)$ de probabilidade pelo teste $\mathrm{F}$ &
\end{tabular}


Os valores médios da capacidade preditiva das 20 reamostragens foram altos para todas as metodologias. As capacidades preditivas foram maiores para a altura de planta que para a altura de espiga. Pelo teste de comparação de médias de Tukey, o GWAS|GS, o BayesB e o LASSO Bayesiano apresentaram capacidades preditivas que não diferiram entre si, mas que foram maiores que a do G-BLUP convencional para a altura de planta. Para a altura de espiga, as capacidades preditivas do GWAS $\mid \mathrm{GS}$, do BayesB e do LASSO Bayesiano também não diferiram entre si. Entretanto, o LASSO não foi superior ao o G-BLUP convencional (Tabela 14).

Tabela 14 - Teste de comparação de médias de Tukey entre métodos de seleção genômica (G-BLUP, GWAS|GS, BayesB e LASSO), para altura de planta e altura de espiga em híbridos de milho tropical

\begin{tabular}{lcc}
\hline \multicolumn{1}{c}{ Método de GS } & Altura de planta* & Altura de espiga* \\
\hline GWAS|GS & $0,804^{\mathrm{A}}$ & $0,790^{\mathrm{A}}$ \\
BayesB & $0,802^{\mathrm{A}}$ & $0,791^{\mathrm{A}}$ \\
LASSO & $0,802^{\mathrm{A}}$ & $0,787^{\mathrm{AB}}$ \\
G-BLUP & $0,795^{\mathrm{B}}$ & $0,782^{\mathrm{B}}$ \\
\hline * - médias seguidas pela mesma letra na coluna não diferem entre si a 5\% de significância pelo teste de Tukey
\end{tabular}

\subsubsection{Coincidência e ganhos com a seleção}

A correspondência entre a seleção fenotípica e a genômica foi estimada por meio da coincidência entre os 11 indivíduos (10\%) superiores que teriam sido selecionados com base em seus valores genotípicos e valores genéticos genômicos (de todos os cenários de seleção genômica). Foram também estimados os coeficientes de correlação de postos de Spearman do conjunto de indivíduos avaliados.

Houve grande coincidência entre os indivíduos selecionados pelas metodologias de seleção genômica (acima de 89\%) para as duas características. A coincidência entre indivíduos selecionados pela GS e seleção fenotípica foi maior para altura de plantas que para altura de espiga, acompanhando a herdabilidade destas características. No geral, as coincidências de seleção fenotípica e genômica foram razoáveis (66,82 a 69,09\% para altura de plantas e 59,55 a 60,45\% para altura de espiga), considerando que o número de indivíduos selecionados corresponde aproximadamente a apenas 10\% do total. As metodologias com maior correspondência com a seleção fenotípica foram o G-BLUP para altura de plantas $(69,09 \%)$ e BayesB para altura de espigas (60,45\%) (Tabela 15 - diagonal superior).

Algumas correlações entre ordenamentos de metodologias de GS foi perfeita devido aos ajustes para duas casas decimais. A correlação entre os VGGs das metodologias de GS e 
os valores genotípicos da análise fenotípica foram praticamente os mesmos, tanto para altura de planta $(0,77)$ como para altura de espiga $(\cong 0,78)$ (Tabela 15 - diagonal inferior).

Tabela 15 - Coincidência de seleção dos 11 melhores híbridos (diagonal superior) e coeficiente de correlação de Spearman para o conjunto completo de indivíduos (do grupo de validação) (diagonal inferior) com base nos valores genotípicos obtidos na análise fenotípica e valores genéticos genômicos obtidos nas metodologias de seleção genômica (G-BLUP, GWAS|GS, BayesB e LASSO Bayesiano) para altura de plantas, altura de espiga e produtividade de grãos em híbridos de milho tropical

\section{Altura de espiga}

\begin{tabular}{cccccc}
\hline & G-BLUP & GWAS|GS & BayesB & LASSO & Fenotípico \\
\cline { 2 - 6 } G-BLUP & - & $89,09 \%$ & $94,09 \%$ & $93,64 \%$ & $60,00 \%$ \\
GWAS|GS & 0,98 & - & $90,45 \%$ & $89,09 \%$ & $59,55 \%$ \\
BayesB & 0,99 & 0,98 & - & $97,73 \%$ & $60,45 \%$ \\
LASSO & 0,99 & 0,98 & 1,00 & - & $59,55 \%$ \\
Fenotípico & 0,78 & 0,77 & 0,78 & 0,78 & - \\
\hline \multicolumn{7}{c}{ Altura de planta } \\
\hline G-BLUP & G-BLUP & GWAS|GS & BayesB & LASSO & Fenotípico \\
\cline { 2 - 6 } GWAS|GS & 0,98 & $90,00 \%$ & $92,27 \%$ & $93,18 \%$ & $69,09 \%$ \\
BayesB & 1,00 & - & $90,45 \%$ & $90,00 \%$ & $66,82 \%$ \\
LASSO & 1,00 & 0,98 & - & $97,27 \%$ & $67,27 \%$ \\
Fenotípico & 0,77 & 0,77 & 1,00 & - & $66,82 \%$ \\
\hline
\end{tabular}

Dada a existência de variabilidade genética entre os genótipos para as características avaliadas, foi estimado o ganho que seria obtido com a seleção fenotípica e genômica (Tabela 16). Os ganhos de seleção fenotípica foram $10,45 \mathrm{~cm}$ para altura de planta e $13,14 \mathrm{~cm}$ para altura de espiga. Os ganhos com a seleção considerando os indivíduos que seriam escolhidos pela seleção genômica variaram de 10,38 cm (G-BLUP) a 10,49 cm (BayesB) para altura de espiga e 8,41 cm (LASSO) a 8,53 cm (G-BLUP) para altura de planta. O G-BLUP convencional e o BayesB foram os que apresentaram maiores ganhos, correspondendo a $79,87 \%$ do ganho da seleção fenotípica para altura de espiga (BayesB) e 84,91\% para altura de espiga (G-BLUP).

Tabela 16 - Ganhos com a seleção (em cm) dos 11 genótipos superiores considerando a seleção fenotípica e as metodologias de seleção genômica G-BLUP, GWAS|GS, LASSO Bayesiano e BayesB para altura de planta e altura de espiga e para seleção fenotípica com base nos valores genéticos em híbridos de milho tropical

\begin{tabular}{lccccc}
\hline \multirow{2}{*}{ Característica } & \multicolumn{4}{c}{ Genômica } & Fenotípica \\
\cline { 2 - 6 } & G-BLUP & GWAS|GS & BayesB & LASSO & BLUP \\
\hline Altura de espiga & $10,38^{1}(79,01)^{2}$ & $10,45(79,56)$ & $10,49(79,87)$ & $10,42(79,28)$ & 13,14 \\
Altura de planta & $8,53(84,91)$ & $8,49(84,50)$ & $8,47(84,28)$ & $8,41(83,70)$ & 10,45 \\
\hline - em centímetros & & & \\
2- porcentagem relativa a seleção fenotípica (100\%)
\end{tabular}


Considerando o esquema recorrente de seleção, foi observada alta eficiência relativa da GS frente à Seleção Recorrente Fenotípica para as duas características avaliadas (Tabela 17). A eficiência relativa das metodologias de seleção genômica variaram de $251,11 \%$ a $254,72 \%$ para a altura de plantas. Para altura de espiga, as eficiências relativas foram menores, variando de $237,03 \%$ a 239,61 . As metodologias G-BLUP e BayesB foram as que apresentaram melhores resultados devido a seus maiores ganhos previamente expostos.

Tabela 17 - Eficiência relativa $\left(E R_{G S \%}\right)$ dos métodos de GS em relação à seleção recorrente com avaliação fenotípica (SRFen) para altura de planta (AP) e altura de espiga (AE) em híbridos de milho tropical

\begin{tabular}{cccc}
\hline Estimativa & Metodologia & Altura de espiga & Altura de planta \\
\hline \multirow{3}{*}{$E R_{G S \%}$} & G-BLUP & 237,03 & 254,72 \\
& GWAS|GS & 238,67 & 253,50 \\
& BayesB & 239,61 & 252,84 \\
& LASSO & 237,63 & 251,11 \\
\hline
\end{tabular}

\subsubsection{Discussão}

\subsubsection{Análise fenotípica}

Foi avaliado número considerável de combinações hibridas (452), as quais apresentaram diferenças genéticas significativas para as três características. Assim, a existência de variabilidade indica a possibilidade de seleção e melhoramento. Estes genótipos foram avaliados em localidades distintas consideradas como fator de efeito aleatório. Com essa suposição busca-se a seleção genótipos que possam ser cultivados em toda e qualquer região representada pelo conjunto de localidades avaliadas. O componente "local" poderia ter sido avaliado como fator de efeito fixo, buscando a seleção de genótipos para locais específicos com aproveitamento da interação entre eles, fator também significativo da análise fenotípica.

Apesar do maior número de locais empregados na avaliação da produtividade de grãos, as herdabilidades no sentido amplo da altura de planta e altura de espiga foram maiores a nível de indivíduo e média de locais. Este fato é esperado devido ao maior efeito do ambiente sobre os componentes que determinam a produtividade (HALLAUER; CARENA; MIRANDA FILHO, 2010). Foi observado que a herdabilidade a nível de médias de locais no sentido amplo aumentou em relação a herdabilidade individual, o que pode indicar que apesar de haver efeito significativo da interação genótipo $\times$ local, existe razoável correlação entre as médias dos tratamentos nos diferentes locais, ou seja, interação do tipo simples. 
As acurácias experimentais $\left(\hat{r}_{g g}\right)$ foram altas, indicando que a condução experimental foi boa o suficiente para seleção confiável dos melhores materiais. Como discutido, a produtividade de grãos é naturalmente mais sujeita aos efeitos ambientais. Entretanto, a avaliação em maior número de locais fez com que esta apresentasse acurácia semelhante às demais características. $\mathrm{O}$ coeficiente de variação experimental $\left(C V_{\varepsilon} \%\right)$, apesar de ser uma medida mais simples que a acurácia, reiterou a boa condução experimental.

A viabilidade da seleção fenotípica é dependente de acurácias elevadas, como as aqui observadas. Entretanto, para que estes níveis de acurácia fossem alcançados, o experimento teve de ser avaliado com repetições e em vários locais. Um dos problemas da seleção fenotípica é a redução do tamanho efetivo em prol do aumento da acurácia seletiva (LORENZ, 2013). Neste sentido, a seleção genômica é uma ferramenta que pode viabilizar a seleção em populações com tamanhos efetivos significativamente maiores, resultando em maiores ganhos de seleção e possibilidade de obtenção de combinações hibridas superiores.

\subsubsection{Arquitetura genética das características}

Objetivou-se com este trabalho avaliar a utilidade do conhecimento da arquitetura genética para a condução da seleção baseada em marcadores moleculares. A correlação entre altura de planta e altura de espiga é um evento bastante conhecido experimentalmente (HALLAUER; CARENA; MIRANDA FILHO, 2010) e estudos da arquitetura genética destas características demonstraram haver alta associação a nível genômico (CAI et al., 2012; PEIFFER et al., 2014). A identificação de marcadores moleculares comuns associados a QTL das duas características é mais uma prova dessa estreita relação genética (Tabela 10 e 11; Figura 1). Portanto, é esperado comportamento semelhante das predições da GS sobre estas metodologias.
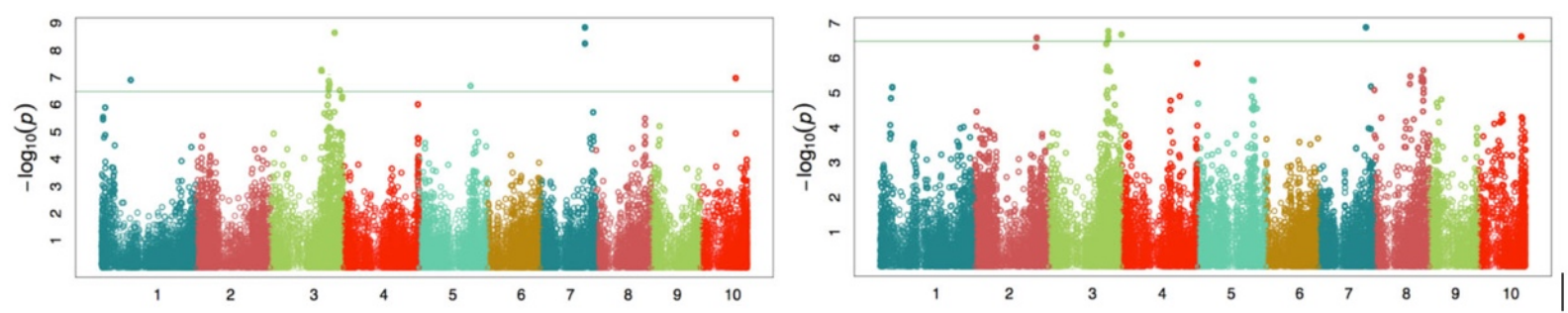

Figura 1 - Manhatan Plot de GWAS para altura de planta (esquerda) e altura de espiga (direita) em 452 híbridos de milho tropical genotipados com 30.467 marcadores SNP distribuídos pelos dez cromossomos

Várias mutações gênicas de grande efeito foram identificadas controlando a altura de plantas de milho (MULTANI et al., 2003). Entretanto, essas variantes são pouco comuns, 
possivelmente devido a sua rápida perda ou fixação (PEIFFER et al., 2014), principalmente devido a seleção direcional dos programas de melhoramento. Foi descoberta quantidade considerável de associações significativas a QTL para altura de planta na população estudada. Entretanto, o locus de maior efeito explica apenas $0,0416 \%$ da variação fenotípica. Para altura de espiga a situação é semelhante, em que o QTL mais efetivo representa $0,0316 \%$ da variação. Esses valores corroboram o fato de que genes de maior efeito já tenham sido fixados para um de seus alelos. Com isto, os efeitos gênicos atuando e ainda segregantes para estas características tendem a ser relativamente homogêneos com elevado grau de poligenicidade (PEIFFER et al., 2014).

\subsubsection{Capacidade preditiva dos métodos de GS}

Foi observado que a modelagem diferencial dos marcadores de efeito significativo resultou em melhor ajuste do BLUP genômico. Considerar marcadores significativos como de efeito fixo resultou em capacidade preditiva semelhante à do LASSO Bayesiano e do BayesB e maiores que a do G-BLUP convencional para as duas características estudadas. Spindel et al. (2016) notaram que existe vantagem preditiva no uso de marcadores significativos como fator fixo. Estes autores indicam que a identificação destes genes na própria população de treinamento, como aqui realizado, resulta em maiores capacidades preditivas do que o uso de informações obtidas em experimentos em populações distintas. É notável que esta técnica possa proporcionar maior capacidade preditiva, mas sua eficiência está sujeita a condições restritivas que devem ser consideradas em sua realização.

Foi demonstrado por simulações que, sob valores altos de herdabilidade (BERNARDO, 2014; HENGDE et al., 2015) e alta porcentagem da variância genética explicada pelos genes de maior efeito (BERNARDO, 2014; SPINDEL et al., 2016), realizar a modelagem específica melhora consideravelmente a eficiência de predição. Os valores de herdabilidade obtidos para a altura de planta e altura de espiga foram altos. Entretanto a soma da variação explicada pelos marcadores de efeito significativo representam menos de $0,5 \%$ da variação fenotípica para as duas características.

Foi observado também um comportamento semelhante entre GWAS $\mid \mathrm{GS}$, BayesB e LASSO, indicando que a modelagem diferenciada de SNPs de efeito significativos de certa forma aproxima estas metodologias. Hengde et al. (2015) observaram que o G-BLUP com modelagem específica de genes de maior efeito e o método BayesB apresentam 
comportamento semelhante frente a alteração no número de QTL controlando a característica, reiterando os resultados obtidos neste estudo.

\subsubsection{Coincidência e ganho com seleção}

Foi observada constância entre os ordenamentos dos VGG das metodologias de GS (Tabela 15). Em teoria, quando a arquitetura genética é homogênea as metodologias G-BLUP (ou seu equivalente, RR-BLUP) e LASSO tendem a ter ordenamento semelhante. O mesmo ocorre para G-BLUP e BayesB quando a arquitetura genética é homogênea e as informações $a$ priori não são informativas (RESENDE et al., 2012a).

As metodologias de GS não proporcionaram correlação de postos consideravelmente distintos com a análise fenotípica. Entretanto, observou-se maior coincidência de seleção do G-BLUP convencional e do BayesB com a seleção fenotípica para a intensidade de seleção considerada. Assim, o método com maior capacidade preditiva não é necessariamente o mesmo com maior coincidência de seleção com a análise fenotípica.

Apesar da coincidência de seleção genômica e fenotípica ter sido de 66,82 a 69,09\% no caso da altura de plantas, os ganhos de seleção que teriam sido obtidos com seu uso foram de pelo menos $83,7 \%$ frente ao ganho com seleção fenotípica, valor bastante satisfatório. Para a altura de espiga o comportamento foi semelhante, em que as coincidências de seleção foram de 59,55 a $60,45 \%$, e com ganhos com a seleção acima de 79,01\% quando comparados à seleção fenotípica. A diferença na magnitude da coincidência de seleção e do ganho de seleção deve-se provavelmente à similaridade do valor genotípico dos indivíduos superiores.

Foi utilizada a intensidade de seleção de aproximadamente 10\% (11 indivíduos) para a estimação da coincidência de ganho de seleção. Todavia, é valido considerar que intensidades diferentes modificam os índices de resposta. A diminuição da intensidade leva a maior coincidência de indivíduos escolhidos pela seleção fenotípica e genômica, bem como o maior ganho relativo à seleção fenotípica (dados não mostrados). Estes resultados indicam que em altas intensidades de seleção, a GS pode apresentar baixa correspondência com a seleção fenotípica, funcionando melhor como uma metodologia de eliminação de genótipos inferiores. As metodologias de GS apresentaram comportamento parecido quanto a coincidência e ganho relativo com a variação da intensidade de seleção. Ademais, nenhuma metodologia se manteve como mais eficiente considerando várias intensidades de seleção, não sendo evidenciada a superioridade de uma delas como descrito para intensidade de seleção de $10 \%$. 
Os ganhos de seleção supracitados são relativos a uma única geração. Considerando a mesma intensidade de seleção (10\%), a eficiência relativa da seleção genômica sobre a fenotípica foi extremamente alta (acima de 237\%), apenas variando o tempo que as metodologias requerem para um ciclo de seleção. No esquema recorrente de melhoramento, além de ciclos de seleção de menor duração, a GS também proporciona maior coincidência entre as unidades de seleção (US) e recombinação (UR) e viabiliza a seleção em populações de grande tamanho efetivo. Desta forma, maior variabilidade genética pode ser explorada, possibilitando maiores intensidades de seleção (FRITSCHE-NETO et al., 2012). Estes fatores não foram aqui explorados, mas aumentam ainda mais a eficiência relativa da GS, expressando a magnitude na qual a GS pode acelerar o progresso genético. Como prova da eficiência do método, há o trabalho de Beyene et al. (2015), que observaram ganhos anuais de três a sete vezes maiores que na seleção fenotípica.

\subsubsection{Considerações quanto ao uso das metodologias}

As metodologias de seleção genômica utilizadas apresentaram-se adequadas para predição da altura de planta e altura de espiga em milho com elevadas capacidades preditivas. A metodologia GWAS $\mid$ GS apresentou bons resultados. No entanto, ela não foi capaz de superar as metodologias Bayesianas. Além disso, existem algumas ressalvas à sua utilização, como, por exemplo, a análise de associação genômica é por definição baseada em germoplasmas diversos, o que pode prejudicar seu uso direto em conjuntos limitados de genótipos elite, como em programas de melhoramento. Deve-se também considerar que a forma de realização da GWAS, a qual é dependente de diversos critérios a serem definidos pelo pesquisador, pode tornar a identificação de QTL subjetiva e conduzir a resultados variados. Ainda assim, não é garantida a identificação de marcadores de efeito significativo, como aqui observado para a produtividade de grãos. Para estas situações, aumentar a permissibilidade e selecionar marcas mesmo que estas não sejam significativas não é vantajoso (SPINDEL et al., 2016).

O conjunto de marcas de efeito significativo sobre o fenótipo foi modelado somente como fator de efeito fixo, pois, considerá-las com efeito aleatório exigiria o cômputo de uma segunda matriz de parentesco genômico derivado apenas destas poucas marcas. Foi observado por Zhang et al. (2015) que a capacidade preditiva do G-BLUP é aumentada quando aplica-se maior peso a marcadores de maior efeito na formação da matriz de parentesco genômica, tornando-a específica para cada característica e de certa forma acomodando a arquitetura 
genética. Neste contexto, a modelagem destas marcas como efeito fixo no G-BLUP, excluindo-as da formação da matriz de parentesco genômico, pode não ser o ideal, sendo requerido o estudo de suas implicações.

Considerando a semelhança da capacidade preditiva do LASSO Bayesiano, BayesB e GWAS|GS, o uso das metodologias Bayesianas é mais indicado pois são procedimentos únicos (one step), e no caso do LASSO, poucas informações são necessárias a priori devido a sua capacidade de estimação dos parâmetros com base nos próprios dados (RESENDE et al., 2012a). Estas metodologias trabalham com arquitetura genética flexível e seleção direta de covariáveis, vantagens operacionais bastante interessantes. Entretanto, podem apresentar elevada demanda computacional.

Por outro lado, deve-se considerar que o G-BLUP é um método simples e rápido, e mesmo assim proporcionou capacidade preditiva, coincidência de seleção e ordenamento semelhantes ou mesmo superior aos demais. Esta metodologia é bastante confiável e eficiente na predição de características complexas em indivíduos altamente relacionados como nas populações sintéticas dos programas de melhoramento (DAETWYLER et al., 2013). Pode-se afirmar que, apesar de serem características oligogênicas, altura de plantas e altura de espiga aproximam-se do princípio infinitesimal considerado pelo G-BLUP. Diante do exposto, conclui-se que o acréscimo de esforço na realização da metodologia GWAS|GS não é compensatória frente ao aumento de capacidade preditiva que ela proporciona.

\subsection{Conclusões}

- A modelagem específica de SNPs de efeito significativo identificados por GWAS melhora a capacidade preditiva do G-BLUP em pequena magnitude.

- As metodologias de seleção genômica avaliadas foram eficazes na predição de características oligogênicas em híbridos de milho, apresentando capacidades preditivas e ganhos com seleção semelhantes, sendo o G-BLUP convencional o mais indicado por sua facilidade de condução. 


\section{Referências}

BERNARDO, R. Molecular markers and selection for complex traits in plants: Learning from the last 20 years. Crop Science, Madison, v. 48, n. 5, p. 1649-1664, 2008.

. Genomewide selection when major genes are known. Crop Science, Madison, v. 54, n. 1, p. 68-75, 2014.

BEYENE, Y.; SEMAGN, K.; MUGO, S.; PRASANNA, B.M.; TAREKEGNE, A.; GAKUNGA, J.; SEHABIAGUE, P.; MEISEL, B.; OIKEH, S.O.; OLSEN, M.; CROSSA, J. Performance and grain yield stability of maize populations developed using marker-assisted recurrent selection and pedigree selection procedures. Euphytica, Wageningen, v. 208, n. 2, p. 285-297, 2015.

BLONDEL, M.; ONOGI, A.; IWATA, H.; UEDA, N. A ranking approach to genomic selection. PloS One, San Francisco, v. 10, n. 6, p. 1-23, 2015.

BROWNING, B.L.; BROWNING, S.R. A unified approach to genotype imputation and haplotype-phase inference for large data sets of trios and unrelated individuals. The American Journal of Human Genetics, Boston, v. 84, n. 2, p. 210-223, 2009.

CAI, H.; CHU, Q.; GU, R.; YUAN, L.; LIU, J.; ZHANG, X.; CHEN, F.; MI, G.; ZHANG, F. Identification of QTLs for plant height, ear height and grain yield in maize (Zea mays L.) in response to nitrogen and phosphorus supply. Plant Breeding, Malden, v. 131, n. 4, p. 502$510,2012$.

DAETWYLER, H.D.; CALUS, M.P.L.; PONG-WONG, R.; DE LOS CAMPOS, G.; HICKEY, J.M. Genomic prediction in animals and plants: simulation of data, validation, reporting, and benchmarking. Genetics, Austin, v. 193, n. 2, p. 347-365, 2013.

ENDELMAN, J.B. Ridge regression and other Kernels for genomic selection with R package rrBLUP. The Plant Genome Journal, Madison, v. 4, n. 3, p. 250-255, 2011.

FRITSCHE-NETO, R. Seleção genômica ampla e novos métodos de melhoramento do milho. 2011. 28 p. Tese (Doutorado em Genética e Melhoramento) - Universidade Federal de Viçosa, Viçosa, 2011.

FRITSCHE-NETO, R.; RESENDE, M.D.V. de; MIRANDA, G.V.; DOVALE, J.C. Seleção genômica ampla e novos métodos de melhoramento do milho. Revista Ceres, Viçosa, v. 59, n. 6, p. 794-802, 2012.

FRITSCHE-NETO, R.; VALE, J.C. do; LANES, É.C.M. de; RESENDE, M.D.V. de; MIRANDA, G.V. Genome-wide selection for tropical maize root traits under conditions of nitrogen and phosphorus stress. Acta Scientiarum. Agronomy, Maringá, v. 34, n. 4, p. 389$395,2012$.

GILMOUR, A.R.; GOGEL, B.J.; CULLIS, B.R.; THOMPSON, R. Asreml user guide release 3.0. Hemel Hempstead: VSN International, 2009. 372 p. 
GOWDA, M.; DAS, B.; MAKUMBI, D.; BABU, R.; SEMAGN, K.; MAHUKU, G.;

OLSEN, M.S.; BRIGHT, J.M.; BEYENE, Y.; PRASANNA, B.M. Genome-wide association and genomic prediction of resistance to maize lethal necrosis disease in tropical maize germplasm. Theoretical and Applied Genetics, Berlin, v. 128, n. 10, p. 1957-1968, 2015.

HALLAUER, A.R.; CARENA, M.J.; MIRANDA FILHO, J.B. Quantitative genetics in maize breeding. $3^{\text {rd }}$ ed. New York: Springer-Verlag, 2010. v. 6, 664 p.

HAYES, B.; GODDARD, M. Genome-wide association and genomic selection in animal breeding. Genome, Ottawa, v. 53, n. 11, p. 876-883, 2010.

HENGDE, L.; WANG, J.; BAO, Z. A novel genomic selection method combining GBLUP and LASSO. Genetica, The Hague, v. 143, n. 3, p. 299-304, 2015.

LANDE, R.; THOMPSON, R. Efficiency of marker-assisted selection in the improvement of quantitative traits. Genetics, Austin, v. 124, n. 3, p. 743-756, 1990.

LEGARRA, A.; ROBERT-GRANIÉ, C.; CROISEAU, P.; GUILLAUME, F.; FRITZ, S. Improved Lasso for genomic selection. Genetics Research, Cambridge, v. 93, n. 1, p. 77-87, 2011.

LI, H.; PENG, Z.; YANG, X.; WANG, W.; FU, J.; WANG, J.; HAN, Y.; CHAI, Y.; GUO, T.; YANG, N.; LIU, J.; WARBURTON, M.L.; CHENG, Y.; HAO, X.; ZHANG, P.; ZHAO, J.; LIU, Y.; WANG, G.; LI, J.; YAN, J. Genome-wide association study dissects the genetic architecture of oil biosynthesis in maize kernels. Nature Genetics, New York, v. 45, n. 1, p. 43-50, 2013.

LIPKA, A.E.; TIAN, F.; WANG, Q.; PEIFFER, J.; LI, M.; BRADBURY, P.J.; GORE, M.A.; BUCKLER, E.S.; ZHANG, Z. GAPIT: genome association and prediction integrated tool.

Bioinformatics, Oxford, v. 28, n. 18, p. 2397-2399, 2012.

LORENZ, A.J. Resource allocation for maximizing prediction accuracy and genetic gain of genomic selection in plant breeding: a simulation experiment. G3, Bethesda, v. 3, n. 3, p. 481-491, 2013.

MAMMADOV, J.; SUN, X.; GAO, Y.; OCHSENFELD, C.; BAKKER, E.; REN, R.; FLORA, J.; WANG, X.; KUMPATLA, S.; MEYER, D.; THOMPSON, S. Combining powers of linkage and association mapping for precise dissection of QTL controlling resistance to gray leaf spot disease in maize (Zea mays L.). BMC Genomics, London, v. 16, n. 1, p. 1-16, 2015.

MEUWISSEN, T.H.E.; HAYES, B.J.; GODDARD, M.E. Prediction of total genetic value using genome-wide dense marker maps. Genetics, Austin, v. 157, n. 4, p. 1819-1829, 2001.

MULTANI, D.S.; BRIGGS, S.P.; CHAMBERLIN, M.A.; BLAKESLEE, J.J.; MURPHY, A.S.; JOHAL, G.S. Loss of an MDR transporter in compact stalks of maize br2 and sorghum dw3 mutants. Science, Washington, v. 302, n. 5642, p. 81-84, 2003. 
PACE, J.; GARDNER, C.; ROMAY, C.; GANAPATHYSUBRAMANIAN, B.; LÜBBERSTEDT, T. Genome-wide association analysis of seedling root development in maize (Zea mays L.). BMC Genomics, London, v. 16, n. 1, p. 16-47, 2015.

PARK, T.; CASELLA, G. The Bayesian Lasso. Journal of the American Statistical Association, Washington, v. 103, n. 482, p. 681-686, 2008.

PEIFFER, J.A.; ROMAY, M.C.; GORE, M.A.; FLINT-GARCIA, S.A.; ZHANG, Z.; MILLARD, M.J.; GARDNER, C.A.C.; MCMULLEN, M.D.; HOLLAND, J.B.; BRADBURY, P.J.; BUCKLER, E.S. The genetic architecture of maize height. Genetics, Austin, v. 196, n. 4, p. 1337-1356, 2014.

PÉREZ, P.; DE LOS CAMPOS, G. Genome-wide regression and prediction with the BGLR statistical package. Genetics, Austin, v. 198, n. 2, p. 483-495, 2014.

PIMENTEL-GOMES, F. Curso de estatística experimental. 15. ed. Piracicaba: FEALQ, 2009. 451p.

R CORE TEAM. R: a language and environment for statistical computing. Vienna: R Foundation for Statistical Computing, 2014.

RESENDE, M.D.V. Matemática e estatística na análise de experimentos e no melhoramento genético. Colombo: Embrapa Florestas, 2007. 561 p.

RESENDE, M.D.V.; DUARTE, J.B. Precisão e controle de qualidade em experimentos de avaliação de cultivares. Pesquisa Agropecuária Tropical, Goiânia, v. 37, n. 3, p. 182-194, 2007.

RESENDE, M.D.V.; SILVA, F.F.; RESENDE JÚNIOR, M.F.R. Seleção Genômica Ampla (GWS). In: BORÉM, A.; FRITSCHE-NETO, R. (Ed.). Biotecnologia aplicada ao melhoramento de plantas. Viçosa: Suprema Gráfica e Editora, 2013. p. 336.

RESENDE, M.D.V.; SILVA, F.F.; LOPES, P.S.; AZEVEDO, C.F. Seleção genômica ampla (gws) via modelos mistos (reml/blup), inferência bayesiana $(\mathrm{mcmc})$, regressão aleatória multivariada e estatística espacial. Viçosa: Universidade Federal de Viçosa, Departamento de Estatística, 2012a. p. 291.

RESENDE, M.F.R.; MUÑOZ, P.; RESENDE, M.D.V; GARRICK, D.J.; FERNANDO, R.L.; DAVIS, J.M.; JOKELA, E.J.; MARTIN, T.A.; PETER, G.F.; KIRST, M. Accuracy of genomic selection methods in a standard data set of loblolly pine (Pinus taeda L.). Genetics, Austin, v. 190, n. 4, p. 1503-1510, 2012 b.

SCHRAG, T.A.; FRISCH, M.; DHILLON, B.S.; MELCHINGER, A.E. Marker-based prediction of hybrid performance in maize single-crosses involving doubled haploids. Maydica, Bergamo, v. 54, n. 2/3, p. 353-362, 2009.

SPINDEL, J.E.; BEGUM, H.; AKDEMIR, D.; COLLARD, B.; REDOÑA, E.; JANNINK, J.L.; MCCOUCH, S. Genome - wide prediction models that incorporate de novo GWAS are a powerful new tool for tropical rice improvement. Heredity, Edinburgh, v. 116, n. 4, p. 395408, 2016. 
TIAN, F.; BRADBURY, P.J.; BROWN, P.J.; HUNG, H.; SUN, Q.; FLINT-GARCIA, S.; ROCHEFORD, T.R.; MCMULLEN, M.D.; HOLLAND, J.B.; BUCKLER, E.S. Genomewide association study of leaf architecture in the maize nested association mapping population. Nature Genetics, New York, v. 43, n. 2, p. 159-162, 2011.

UNTERSEER, S.; BAUER, E.; HABERER, G.; SEIDEL, M.; KNAAK, C.; OUZUNOVA, M.; MEITINGER, T.; STROM, T.M.; FRIES, R.; PAUSCH, H.; BERTANI, C.; DAVASSI, A.; MAYER, K.F.; SCHÖN, C.-C. A powerful tool for genome analysis in maize: development and evaluation of the high density $600 \mathrm{k}$ SNP genotyping array. BMC Genomics, London, v. 15, n. 1, p. 823, Jan. 2014.

VANRADEN, P.M. Efficient methods to compute genomic predictions. Journal of Dairy Science, Champaign, v. 91, n. 11, p. 4414-4423, 2008.

WELLER, J.I.; SONG, J.Z.; HEYEN, D.W.; LEWIN, H.A.; RON, M. A new approach to the problem of multiple comparisons in the genetic dissection of complex traits. Genetics, Austin, v. 150 , n. 4, p. 1699-1706, 1998.

WIMMER, V.; ALBRECHT, T.; AUINGER, H.-J.; SCHON, C.-C. synbreed: a framework for the analysis of genomic prediction data using R. Bioinformatics, Oxford, v. 28, n. 15, p. 2086-2087, 2012.

ZHANG, Z.; ERBE, M.; HE, J.; OBER, U.; GAO, N.; ZHANG, H.; SIMIANER, H.; LI, J. Accuracy of whole genome prediction using a genetic architecture enhanced variancecovariance matrix. G3, Bethesda, v. 5, p. 615-627, 2015.

ZHAO, Y.; METTE, M.F.; GOWDA, M.; LONGIN, C.F.H.; REIF, J.C. Bridging the gap between marker-assisted and genomic selection of heading time and plant height in hybrid wheat. Heredity, Edinburgh, v. 112, n. 6, p. 638-645, 2014. 
- A estimação do parâmetro de penalização (shrinkage factor) com base na herdabilidade no sentido restrito resulta em menor eficiência que sua obtenção por REML visando a predição genômica de híbridos simples de milho tropical.

- O uso de valores genotípicos como variável dependente na seleção genômica conduz a maiores capacidades preditivas em híbridos simples de milho tropical.

- A GS apresenta maior eficiência sob baixas intensidades de seleção no melhoramento de híbridos de milho tropical.

- A modelagem específica de SNPs de efeito significativo identificados por GWAS melhora a capacidade preditiva do G-BLUP em pequena magnitude.

- As metodologias de seleção genômica avaliadas foram eficazes na predição de características oligogênicas em híbridos de milho, apresentando capacidades preditivas e ganhos com seleção semelhantes, sendo o G-BLUP convencional o mais indicado por sua facilidade de condução. 